Florida International University FIU Digital Commons

$10-23-2012$

\title{
The Impact of Social Comparison Processes on Hoped-For Possible Selves, Self-Regulatory Processes, and Mental Health Outcomes in Young Adults
}

Rebecca A. Wang

Florida International University, rebecca.wang@aol.com

DOI: $10.25148 /$ etd.FI12120513

Follow this and additional works at: https://digitalcommons.fiu.edu/etd

\section{Recommended Citation}

Wang, Rebecca A., "The Impact of Social Comparison Processes on Hoped-For Possible Selves, Self-Regulatory Processes, and Mental Health Outcomes in Young Adults" (2012). FIU Electronic Theses and Dissertations. 786.

https://digitalcommons.fiu.edu/etd/786 


\section{FLORIDA INTERNATIONAL UNIVERSITY \\ Miami, Florida}

THE IMPACT OF SOCIAL COMPARISON PROCESSES ON HOPED-FOR

POSSIBLE SELVES, SELF-REGULATORY PROCESSES, AND MENTAL HEALTH

OUTCOMES IN YOUNG ADULTS

A dissertation submitted in partial fulfillment of the

requirements for the degree of

DOCTOR OF PHILOSOPHY

in

PSYCHOLOGY

by

Rebecca Ann Wang

2012 
To: Dean Kenneth G. Furton

College of Arts and Sciences

This dissertation, written by Rebecca Ann Wang, and entitled The Impact of Social Comparison Processes on Hoped-For Possible Selves, Self-Regulatory Processes, and Mental Health Outcomes in Young Adults, having been approved in respect to style and intellectual content, is referred to you for judgment.

We have read this dissertation and recommend that it be approved.

$\begin{array}{r}\hline \text { Robert Lickliter } \\ \hline \text { Paulette Johnson } \\ \hline \text { Dionne Stephens } \\ \hline \text { Leslie Frazier, Major Professor }\end{array}$

Date of Defense: October 23, 2012

The dissertation of Rebecca Ann Wang is approved.

Dean Kenneth G. Furton College of Arts and Sciences

Dean Lakshmi Reddi University Graduate School

Florida International University, 2012 


\begin{abstract}
OF THE DISSERTATION
THE IMPACT OF SOCIAL COMPARISON PROCESSES ON HOPED-FOR

POSSIBLE SELVES, SELF-REGULATORY PROCESSES, AND MENTAL HEALTH

OUTCOMES IN YOUNG ADULTS
\end{abstract}

by

Rebecca Ann Wang

Florida International University, 2012

Miami, Florida

\title{
Professor Leslie Frazier, Major Professor
}

In exploring the role of social influences in the development of the self, the current study evaluated whether young adults use social comparisons in developing their hoped-for possible selves and, if so, whether their developmental process correlates with selfregulatory processes and positive mental health outcomes. The current study found the following: (1) the domains of hoped-for possible selves among young adults were related to the gender of the social comparison target, (2) the direction of young adults' social comparison processes (upward or downward) did not significantly influence selfregulatory processes (self-efficacy and outcome expectancy) toward achieving their hoped-for possible selves, (3) strong masculine gender identification related to greater outcome expectancy, while strong feminine gender identification related to both greater self-efficacy and outcome expectancy, and (4) self-efficacy related to less state anxiety, trait anxiety, and depression, while outcome expectancy related only to less trait anxiety. Males and females were found to use traditional gender role identification in forming their hoped-for possible selves. 


\section{TABLE OF CONTENTS}

CHAPTER

PAGE

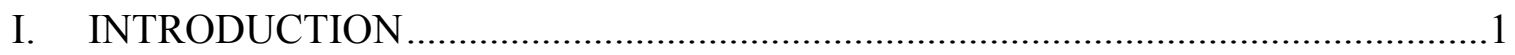

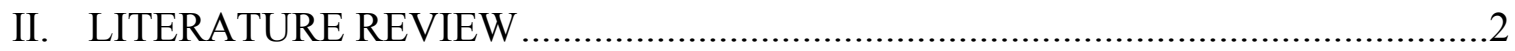

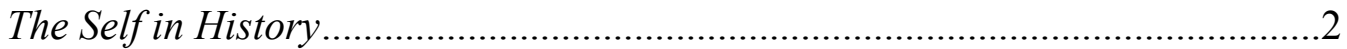

Philosophy and the Self .................................................................................2

Psychoanalysis, Ego Psychology, and the Self ..............................................6

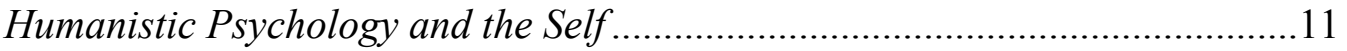

Experimental Social Psychology and the Self ................................................14

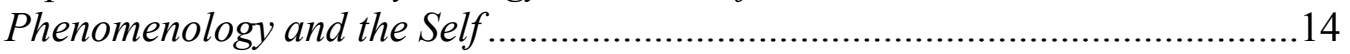

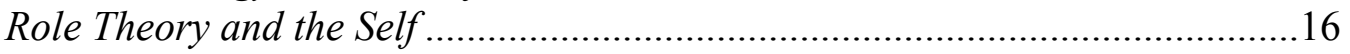

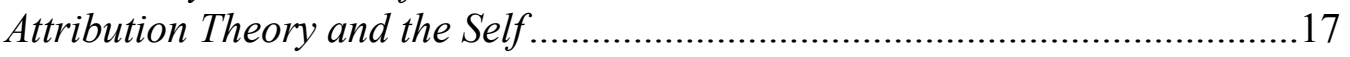

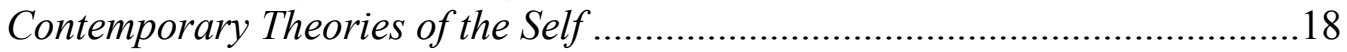

Bandura's Social Cognitive Theory of the Self ...............................................21

Baltes' Life Span Theory of the Self ...............................................................23

Bronfenbrenner's Bioecological Theory of the Self.........................................24

Overview of Possible Selves ..........................................................................26

Possible Selves and Self-regulatory Processes .............................................28

Possible Selves and Psychosocial Outcomes ...................................................30

Social Comparisons and Formation of the Self ................................................30

Upward Social Comparison Processes and the Self ..........................................3

Lateral Social Comparison Processes and the Self ..........................................41

Downward Social Comparison Processes and the Self ....................................42

Gender Schema Theory and the Self ...........................................................45

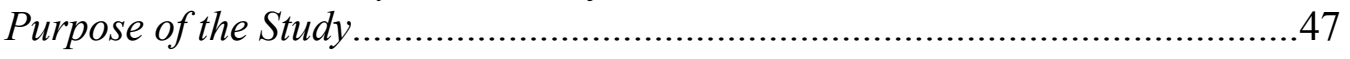

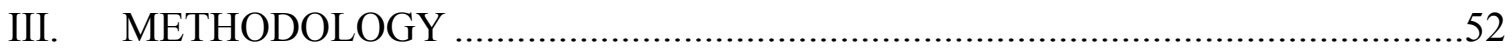

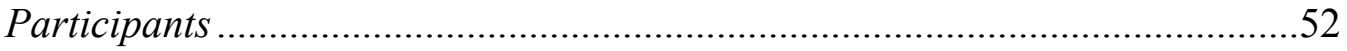

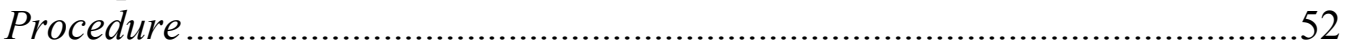

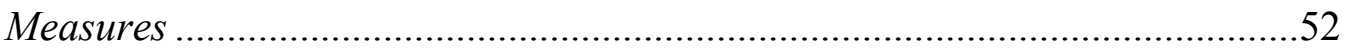

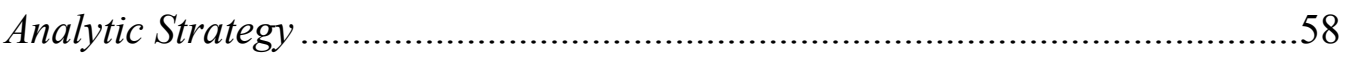

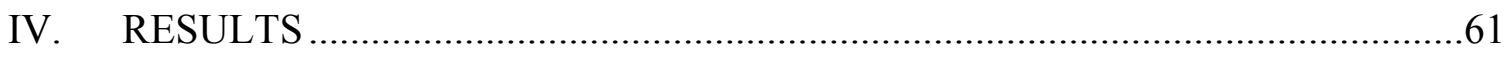

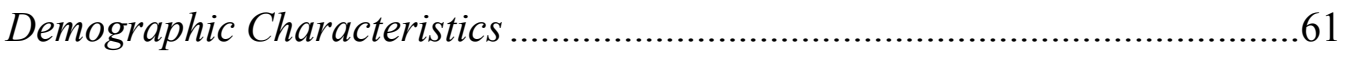

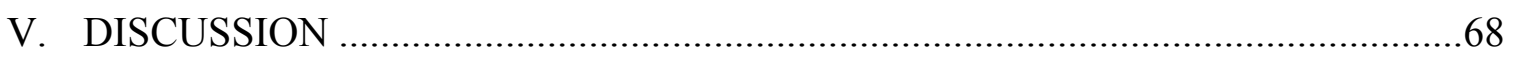

Limitations and Directions for Future Research ......................................70

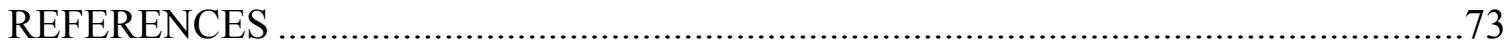

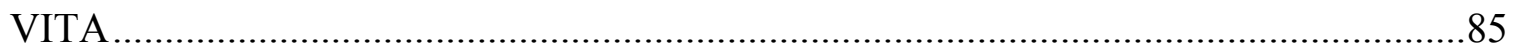




\section{LIST OF TABLES}

TABLE

PAGE

Table 1. Demographic Characteristics of Respondents 80

Table 2. Summary of Cross-tabulation Results for Gender of Social Comparison Target by 5 Hoped-For Possible Self Domains $(\mathrm{N}=110)$.

Table 3. Summary of Correlation Results for Direction of Social Comparison Processes and Self-Regulatory Processes $(\mathrm{N}=155)$.

Table 4. Summary of Correlation Results for BSRI Gender Role Identification and Self-

Regulatory Processes $(\mathrm{N}=164)$. 82

Table 5. Summary of Correlation Results for Self-Regulatory Processes and Mental Health Outcomes $(\mathrm{N}=164)$. 82

Table 6. Multiple Regression Model Summary: Self-Regulatory Processes. 82

Table 7. Multiple Regression Analysis of Self-Regulatory Processes on Independent Variables, Controlling for Demographic Variables: Standardized Coefficients 83

Table 8. Multivariate Tests of Direction of Social Comparison Processes by Gender... 83

Table 9. Multivariate Tests of BSRI Gender Role Identification by Gender 84

Table 10. Multivariate Tests of Self-Regulatory Processes by Gender 84 


\section{INTRODUCTION}

The purpose of my dissertation is to explore the forces which shape one's sense of self and one's possible selves during young adulthood. Recently, self-regulatory and action-oriented approaches to examination of the self have received primary attention, providing theoretical grounding for understanding how and why individuals become active producers of their own developmental process (Brandtstadter \& Lerner, 1999; Frazier \& Hooker, 2006; Frazier, Newman, \& Jaccard, 2007; Heckhausen \& Dweck, 1998; Lerner \& Busch-Rossnagel, 1981). Knowing the teleonomic relevance of certain developmental outcomes helps us to understand the motivational weight of possible selves (Hooker, 1999; Markus \& Nurius, 1986), life goals (Rapkin \& Fischer, 1992), and personal projects (Lawton, Moss, Winter, \& Hoffman, 2002; Little, 1983) in directing individual development along unique developmental trajectories.

Yet, development does not occur in a vacuum. Development is situationally-sensitive and embedded in the sociocultural and historical context. Although early work on identity and self grew out of symbolic interactionism (Cooley, 1902; Dewey, 1896; James, 1890; Mead, 1934), lately the focus on self-motivated development has led to a neglect of interest in the influence of others on the development of the self. Across the lifespan, the importance of others may wax and wane, but, during adolescence and young adulthood, family, peers, and other social forces are especially influential in shaping development (Bronfenbrenner \& Morris, 1998; Furman \& Burhmester, 1985; Payne, 2002; Steen, Kachorek, \& Peterson, 2003). 


\section{LITERATURE REVIEW}

\section{The Self in History}

In the early twentieth century, the concept of the self initially received prominence in the psychoanalytic and symbolic interactionism movements, but interest in the study of the self declined with the rise in popularity of behaviorism from 1920 to 1930. From 1940 to 1950 , research and theorizing of the self experienced a resurgence as a result of the humanistic movement that developed in response to Gordon Allport's (1937) theory proposing that the self is absolutely necessary for effectively addressing the motivational factors involved in human behavior. Seven major psychological perspectives have contributed significantly to the understanding of the concept of self: symbolic interactionism (Baldwin, 1902; Cooley, 1902; Dewey, 1896; Goffman, 1959; James, 1890; Mead, 1925), psychoanalysis (Freud, 1933), ego psychology (Erikson, 1959, 1963, 1968, 1974, 1978, 1982); Fromm, 1941; Jung, 1966), humanistic psychology (Allport, 1955; Maslow, 1954, 1968; Rogers, 1951, 1959), experimental social psychology (Aronson, 1968; Wells \& Marwell, 1976), phenomenology (Gubrium \& Buckholdt, 1977; Natanson, 1970), and role theory (Biddle \& Thomas, 1966; House, 1977; Turner, 1976, 1978). Each of these disciplines must be discussed to provide a comprehensive overview of how the self, in terms of individual and social forces, has been conceptualized over time.

\section{Philosophy and the Self}

The concept of the self dates back to early writings of philosophers who focused on the nature of the human soul. In Buddhist philosophy, dating back to the first century B.C., the self was called sem, or a stream of thoughts which reinforces the image of 
oneself (Chodron, 2000). Even in early Greek philosophy, attempts were being made to formulate a comprehensive theory about what constitutes the soul, in terms of emotional, cognitive, and moral components. Homer's writings during the fifth century B.C. depicting the soul as simply a representation of being alive on a physical human level gradually gave way to an emphasis upon the soul by Plato during the third century B.C. and Aristotle during the fifth century B.C. as being a more complex representation of all living things (Cornford, 1957). Harmony, love, strife, morality, and reason were, according to Aristotle, the elements of human bodily existence which perpetuated individuals toward particular social systems, which, in turn, redefined these elements of the self (Cornford, 1957). Both Plato (Marias, 1967; Durant, 1926) and Aristotle (Barnes, 1984) proposed that individual thinkers cannot be truly understood apart from the social and political systems within which they live and to which they react. Such early philosophical concepts of the soul can be seen in modern developmental contextualist theories which view the self as both acting in a purposeful manner upon others and being influenced by others in one's social environment.

\section{Symbolic Interactionism and the Self}

The symbolic interactionism movement placed emphasis upon the self as the core element for understanding the dynamic relationship between the individual and society (Breytspraak, 1984). Symbolic interactionists believe that, contextually, the self and society "have no reality apart from each other, but are both made by and makers of our society" and that the self is a "uniquely human capacity which depends on our ability to think reflexively about ourselves as objects (Breytspraak, 1984, p. 30)." William James (1890) described the self, in Principles of Psychology, as a dynamic series of interactions 
between the self as both the subjective knower and as the objective known. James (1890) proposed that the self is multidimensional and that we may have many selves influenced by those social groups about which we most care and that these selves are linked in time as present selves and future selves. James (1890) also identified three main parts of the self: its constituents, the feelings they arouse, and the behaviors they prompt. James (1890, as cited in Breytspraak, 1984) regarded self-esteem as coming from a favorable relationship between one's ideal self and one's perceived actual self. James (1890, as cited in Breytspraak, 1984) believed that giving up pretensions may bring as much relief as getting them gratified.

Dewey (1896) was the first symbolic interactionist to bring attention to the inefficient and imprecise use of words and concepts that reflect three historic levels of organization of the self. Dewey (1896) referred to the first level of the self as self-action, or an internal motivating source of action toward goals. The second level of the self, or interaction, refers to the reciprocity between the individual and one's environment in shaping the self (Dewey, 1896). The third level of the self, or transaction, refers to multiple phases of action which exist between various entities in our social world and which are constantly changing based on choices and actions made by the individual (Dewey, 1896). Dewey (1896) viewed the active self as the core of voluntary prosocial behavior directed toward a continuous process of positive change, not out of regard for oneself as an individual but out of regard for the world in which one wishes to live. Dewey (1896) hypothesized that each individual creates a social identity and engages in voluntary actions aimed at trying to make the world a better place. One's social identities differ from another on the basis of the number of interpersonal relationships that are 
recognized versus denied, as well as which personal and social resources are targeted toward one's overall identity development.

Charles Horton Cooley (1902) further explored the self by proposing that we have a social self, or looking glass self, which is any idea, or system of ideas, drawn from our communicative life and consisting of images about oneself derived from others' expressed evaluations. According to Cooley (1902), a person's sense of I is the part of the self which acts with reference to others and is immediately conscious of others' reactions to the self, and a person's sense of me is the reflective self which continually evaluates and reinvents the I sense of self. Cooley (1909) also defined the concept of primary groups as involving frequent intimate, face-to-face association and cooperation with a group of others who significantly impact one's sense of self. Cooley (1909) viewed the self as predominantly influenced by the common life and purpose of the groups within which the self functions. The primary group, according to Cooley (1909), determines the ambitions and the standards of behavior for each individual within this group.

George Herbert Mead (1932) was one of the first theorists to propose that the self cannot exist apart from the communicative process with others, which is achieved through both verbal and nonverbal expression, and that humans engage in role-taking largely developed from the vantage from which others see them. Mead (1932) also viewed the self as an object which exists as a series of patterns of social relations with other selves in one's environment. According to Mead (1932), a person acts toward others as both the subject and object of social interactions, and the subject of this presentation can never appear immediately in conscious experience. Mead (1932) believed that social conduct with others has greater impact on the development of the self 
than does one's introspective sense of self-consciousness. In fact, Mead (1932) hypothesized that, as early as infancy, humans consciously call the attention of others and are consciously affected by others before they are consciously affected by themselves. Mead (1932) went further to delineate three parts of the self: (1) images of the self which a person carries within the mind, (2) images of the self which are created by others, and (3) images of the self which the self embraces.

Erving Goffman (1959) proposed that we have a self which we see as our own and portray to others but that we also have a self which belongs to others and which is shaped by others' attributions about us. Goffman (1959) went further to hypothesize that we also have a truer self, which is the self one would like to be within one's unique developmental trajectories. Goffman (1959) believed that daily social interactions can be compared to an ongoing series of performances, as in a play with various audiences, and that these performances consist of different roles which become the reality of one's self. Goffman (1959) viewed individuals as involved, through their social performances, in continuous purposive and transitional movement from belief to disbelief and from disbelief to belief regarding the confirmation of the key aspects of their identity and the significance of their behaviors. From this perspective, the perceived worth or credibility of one's social roles is shaped by the verbal and nonverbal responses from others, and those social roles which receive the greatest frequency of positive responses from others will tend to become internalized into one's sense of self (Goffman, 1959).

Psychoanalysis, Ego Psychology, and the Self

Sigmund Freud (1900), founder of the psychoanalytic movement, conceptualized the self as composed of an ongoing conflict among the id, ego, and superego. The id is 
entirely unconscious and operates completely on the pleasure principle, which focuses on immediate gratification of primitive urges, such as sleeping, eating, and other acts which bring pleasure, and which is responsible for often illogical and irrational thoughts and behaviors (Freud, 1900). Freud viewed the self in terms of three levels of psychic awareness: the conscious, or what a person is aware of during one particular point in time, the preconscious, or information which is just beneath the surface of awareness and can be easily retrieved, and the unconscious, which is the underlying part of the self which contains one's unmet wishes and expectations. Freud's psychoanalytic theory proposed that our ego is the part of the self which must meet the demands of one's social environment, consisting of parents, peers, teachers, mentors, employers, culture, and society as a whole. Freud's ego could be compared to one's current self, while Freud's superego could be compared to one's possible self, in that the ego is continuously responding to external cues and the superego is the moral and ideal "higher ground" to which an individual aspires and which is largely shaped by others' expectations of appropriate or acceptable behaviors and values (Freud, 1900). Freud's belief that the superego is guided by rewards and sanctions from others is consistent with the current study's emphasis on the role of others in shaping one's self development process.

Carl Jung (1964) regarded the self as emerging from a drive to find unity and wholeness between the conscious and unconscious, represented by a mandala, which pursues growth, order, and completion, or, what Jung called self-realization. The mandala of the self has an outer circle, which is one's conscious, a middle circle, which is one's personal unconscious, and an inner circle, which is the collective unconscious (Jung, 1928). Complete self-realization, according to Jung (1964), is a universal ideal which is 
not attained but pursued throughout life, exists within the collective unconscious of everyone, and represents a balance between rationality and irrationality and between conscious awareness and unconscious images and memories. Jung (1964) believed that the self seeks perfect balance between one's internal and external world, one's conscious and unconscious experiences, good and evil, male and female, lightness and darkness.

Jung (1928) theorized that the formation of the self begins in childhood as a process of knowing, which is constructed upon a conscious connection between psychic contents, which, in early years of life, constitute no continuous form of memory. Jung (1928) asserted that the moment when a child begins to speak of oneself in the first person signifies the continuity of memories which compose the ego, or sense of self. Jung (1928) viewed the ego as an object in conscious awareness and proposed that, only when the contents of one's ego have been charged with energy of their own can the feeling of subjectivity, or a sense of I, evolve. Jung (1928) also proposed that the first stage of conscious awareness consists of recognizing or knowing oneself in a generally chaotic state and that puberty marks the beginning of a realization that one's inner impulses can be met by external limitations which constitute the ego-complex.

Erich Fromm (1941), in Escape from Freedom, proposed that the history of humanity has been one of achieving a greater sense of separation from nature and a sense of self-consciousness, which brings with it the freedom to actualize human possibilities. Fromm (1941) conceptualized the self as being dominated by three basically insoluble existential dichotomies: (1) attempting to explain life after death, while being faced with the inevitability of dying; 
(2) continually seeking self-realization, while being aware that life is too short to fully complete this process; and (3) attempting to solve the problem of aloneness versus union with others. According to Fromm (1941), these existential dichotomies have emerged during the evolution of the human culture, resulting from our attempts to find an answer to our existence and to avoid becoming insane.

Fromm (1941) also proposed that all humans share five basic existential needs in developing a sense of self. First, the need for relatedness is the drive for union with another person or other persons (Fromm, 1941). Secondly, the need for transcendence is the urge to rise above a passive and accidental existence and into the realm of purposefulness and freedom; we can achieve transcendence both through the creation of art, religion, ideas, laws, love, or the production of another human being and through destruction, which occurs through malignant aggression, or killing for reasons other than survival (Fromm, 1941). Thirdly, Fromm (1941) proposed that, because humans evolved as a separate species and lost their home in the natural world, we require rootedness, or feeling at home again in the natural world, and that we can

actively and creatively relate to the world through belongingness and connectedness, resulting in being whole and integrated beings. Fourth, Fromm (1941) believed that the rise of capitalism gave people more economic and political freedom, but that few people achieve a true sense of identity, which is the awareness of oneself as a separate entity in the world. A frame of orientation is a final goal or direction, which enables to act purposefully and consistently throughout life. Finally, the need for a strong frame of orientation enables us to make sense out of random events in our lives, to accept change, and to behave in a purposeful manner throughout life, while a weak frame of orientation 
causes us to seek blame or fault, so that we do not feel out of control (Fromm, 1941). Fromm (1941) believed that positive freedom of the self is achieved through a spontaneous and full expression of one's emotional and rational potentialities.

Erikson (1959) conceptualized the self in terms of the ego, which unifies our present experiences, past self-identities, and anticipated images of our future self. Erikson's (1959) view of the self consists of the body ego, which is one's physical appearance, the ego ideal, which is the comparison of one's real self with what is considered to be one's ideal self, and the ego identity, which consists of one's self-image and how a person behaves in different social roles. Erikson (1959) believed that our ego is a positive force which creates a sense of identity, or a sense of I, and which helps us adapt to life's various conflicts and crises through an integration of both unconscious and conscious experiences.

Erikson's (1959) psychosocial theory proposed that our personality is gradually formed over time and that different traits emerge through unique personal experiences during certain life stages, such as infancy, childhood, adolescence, and adulthood. In each psychosocial stage, there is a conflict between syntonic (harmonious) and dystonic (disruptive) elements, and, at each stage, this conflict either produces a basic strength or results in a core pathology (Erikson, 1959). During the first year of life, basic trust results from one's oral and other physical needs being met by the mother figure and from positive experiences with one's visual and auditory environment, while basic mistrust results from a lack of fit or correspondence between one's needs and one's environment (Erikson, 1959). Hope emerges from the conflict between basic trust and basic mistrust, while withdrawal results from a complete lack of trust in one's caregivers and one's 
environment (Erikson, 1959). During the second and third years of life, autonomy grows out of basic trust and is a sense of personal control, confidence, and faith in the external world, while shame and doubt grow out of basic mistrust and is a sense of selfconsciousness and uncertainty (Erikson, 1959). From ages three to five, initiative is achieved through the mastery of cognitive tasks, interactions with peers, and positive relations with parents and other adults, while guilt is experienced when a child lacks competence or self-confidence in these experiences (Erikson, 1959). From age 6 to puberty, industry is achieved through a willingness to persevere until a certain goal (academic, vocational, interpersonal, intrapersonal, or physical) is completed, and inferiority results from failure or inadequacy in meeting any of these goals (Erikson, 1959). Erikson (1959) believed that the adolescent years are the most pivotal stage in the development of the self, or a sense of identity, and that we draw upon a variety of earlier self-images which developed during our childhood, choosing those parts of the self which we view as positives and those which may not be working for us. This stage is so pivotal, because our social roles, moral beliefs, and personal goals largely determine how our adult developmental process will go.

Humanistic Psychology and the Self

Humanistic psychology has been called the third force in psychology, because it reacted against both Freudian determinism and environmental determinism of learning theory. Humanistic psychologists view the individual as active, purposeful, and selfdetermining. Furthermore, the individual is seen by the humanist as not a passive force influenced by environmental stimuli, but as a dynamic force capable of ongoing growth, reinvention, and creativity. Gordon Allport (1937), a humanistic theorist, has been most 
credited with a re-emphasis on the concept of the self. Allport (1937) believed that the tendency to satisfy biological survival needs, which he termed opportunistic functioning, is much less important than the tendency toward proactive, future-oriented behaviors, which he termed propriate functioning. Propriate comes from the word proprium, which is Allport's (1937) name for that part of the self consisting of what one views as most essential to functioning within the social world.

Allport (1937) proposed that the self has seven functions, which tend to arise at certain times of one's life. Sense of body and self-identity develop in the first two years of life and occur when we see ourselves as individual entities, separate and different from others (Allport, 1937). Self-esteem, developing between ages two and four, is shaped by our sense of competencies compared to others in our social environment (Allport, 1937). Self-extension and self-image, developing between ages four and six, are parts of our identity shaped by those essential to our existence, such as our parents, peers, mentors, and community, and by activities which create a sense of worth and pride (Allport, 1937). These concepts are similar to the looking glass self, or the me as others see me, proposed by Cooley (1902). Rational coping is the sixth function, learned from ages six to twelve, which is shaped by how effectively we manage life's problems, and propriate striving is the final function which develops after age twelve and is shaped by our goals, ideals, plans, vocations, and overall sense of purpose (Allport, 1937).

Abraham Maslow (1943), in his holistic-dynamic theory, proposed that the self is shaped by an internal motivation to fulfill different needs aimed at personal well-being and the pursuit of one's life potential. Holistic refers to understanding people as a combination of many aspects: thoughts, feelings, actions, and experiences with others, 
and dynamic refers to the capacity for ongoing change and growth (Maslow, 1943). Whereas psychodynamic theorists were mainly past-oriented, holistic-dynamic theorists view personality development in terms of behaviors, values, and characteristics aimed at present and future well-being. According to Maslow (1943), motivation can only be understood by looking at from several separate motives, some which may be on an unconscious level. According to Maslow (1943), all people, regardless of culture, are motivated by the same basic needs, which can be arranged in a hierarchy. Lower level needs, or conative needs, are a person's natural tendencies or impulses aimed at reaching one's potential and must be satisfied before higher level needs can be satisfied (Maslow, 1943). Maslow (1968) viewed the self as innately driven toward good, not evil, and believed that each person is capable of the following characteristics: hope, wisdom, creativity, future mindedness, courage, spirituality, and responsibility.

Carl Rogers' (1947) person-centered theory contributed to research on the self by proposing that humans have a formative tendency, which is an innate drive to progress from simpler to more complex forms over time, and a self-actualizing tendency, which is an innate drive to progress toward the fulfillment of one's potential in life, defined by internally-formulated goals and social influences (culture, peers, society, and family). Rogers (1947) created the concept of positive self-regard, which is a person's self-esteem or self-worth achieved by experiencing positive regard from others throughout the developmental process. According to Rogers (1947), without positive self-regard, a person may feel hopeless toward reaching one's potential, which can then lead to depression, anxiety, and other negative mental health outcomes. Rogers (1947) also developed the concepts of the real self, or who you perceive yourself to be and will 
become, and the ideal self, or who you believe you should become. Rogers (1947) believed that incongruity results from a gap between one's real self and ideal self and that a person's mental health lies in the ability to bridge this gap.

Experimental Social Psychology and the Self

Beginning in the 1970's, experimental social psychologists have studied attitudes about the self as they influence self-esteem. Self-esteem has been a focal point in understanding the dynamics of moral behavior and a mediating factor in understanding the effects of various factors on performance on tasks (Wells \& Marwell, 1976). Research on cognitive dissonance has incorporated the self-concept as a central variable in situations involving inconsistencies between one's behaviors and one's self-concept, which includes one's values, beliefs, and morals (Aronson, 1968; Festinger, 1954). Cognitive dissonance theory explains why we change our attitudes to fit our behaviors, even though certain behaviors may conflict with our true beliefs (Festinger, 1954). Attribution theory became another dominant force in experimental social psychology during the 1980's and assumes that people actively perceive actions and behaviors and attempt to make sense of them by assigning causality; attribution processes can be useful in understanding how we maintain an integrated sense of self (Breytspraak, 1984).

\section{Phenomenology and the Self}

The phenomenological perspective, according to Natanson (1970, as cited in Breytspraak, 1984), views time as having meaning insofar as it comes into our consciousness through the "here" and "now" of our awareness of a stream of experience in the continuously changing "experiential world." As Natanson (1970, p. 12, as cited in Breytspraak, 1984) suggested, "temporality is a constitutive force in the construction of 
what is distinctively mine...How close or far 'there' is from 'here' cannot be measured abstractly, for distance is a function of my insertion in the world." According to the phenomenologists, the body is central to the experience of the self, and the body is the unique instrument through which individuals experience their insertion of self into the world and, thus, know the past and expect a future (Breytspraak, 1984). Similar to the symbolic interactionist perspective, the phenomenological perspective views the self as the center of one's relationship with the world and the means by which a person is engaged in the social world; these two perspectives are distinctive in their focus on the question of why and how people acquire common subjective states and common evaluations of the world through processes of negotiation between self and environment (Breytspraak, 1984). The phenomenological perspective is similar to that of George Herbert Mead's symbolic interactionist concept of emergence, which asserts that people do not have a past, but rather an awareness of a past, and not a future, but an expectancy of a future (Breytspraak, 1984).

Edmund Husserl perceived the experience of the self in terms of the "primal now," which includes experiential protentions, or anticipations of the likely future course of experience, and latter retentions, or recollections of our recent past. Husserl believed that our experience of the self consists of anticipations of how your experience will change in given circumstances and recollections of how it has changed in the past. The phenomenological perspective assumes that the only reality is that which is in our consciousness and that things are never separate from actors' experience of them, thus disputing a physical, biological model assuming that the world is a separate reality from the individual (Breytspraak, 1984). Quite contradictory to other previously-described 
social science theories which assume that certain drives, needs, goals, parental and occupational roles and expectations, and social groups shape an individual's self, the phenomenological perspective assumes that aspects of the self are real only insofar as they enter people's language and action and that the self is actively engaged in both responding to and influencing one's external world (Breytspraak, 1984). Gubrium and Buckholdt (1977, as cited in Breytspraak, 1984) believed that one essential difference between the phenomenological and symbolic-interactionist perspectives is that the interactionist, through the focus on processes of negotiation and creativity, places too much emphasis upon getting a stable set of self-definitions from the point of view of others and then committing the self to these definitions.

\section{Role Theory and the Self}

Role theory proposes that individuals occupy positions in society and that their role performance is determined by social norms and demands, by the role performance of others, by those who observe and react to the role performance of others, and by the individual's particular capabilities and personality (Biddle \& Thomas, 1966, as cited in Breytspraak, 1984). Role theory reflects a doctrine of limited social determinism in its focus on the controlling power of one's immediate social environment, in which roles are the key linkages between individuals and society (Breytspraak, 1984). Role theory regards the self either as one's sense of identity resulting from playing one's social roles or as the set of all standards, descriptions, and concepts held by an actor for himself; in either scenario, the self has no meaning apart from its social roles (Biddle \& Thomas, 1966, as cited in Breytspraak, 1984). Role theory has been criticized for its emphasis upon the social system in determining the roles played by an individual (House, 1977, as 
cited in Breytspraak, 1984). Ralph Turner (1976, 1978, as cited in Breytspraak, 1984) has proposed that the self is invested in a role and that the self and role merge inevitably. Role theory has significance in the study of the self through its similarity with the symbolic interactionist perspective and its linkage with social comparison theory. Attribution Theory and the Self

Attribution theory is similar to symbolic interactionism in the study of how people attain a subjective understanding of their social environment and how this subjective understanding influences our behavior (Breytspraak, 1984). Attribution theory differs from symbolic interactionism in its focus on the individual cognitive processes involved in creating meaning through one's social interactions, as opposed to focusing primarily on social influences upon the individual (Breytspraak, 1984). Heider (1944, 1958, as cited in Breytspraak, 1984) proposed that we tend to attribute causality to either personal or environmental factors; if we perceive that the causes lie in the environment, the behavior we are observing tells us little about the actor as a person. Heider $(1944,1958)$ also proposed that there is a bias toward making attributions to stable characteristics of the person, rather than a more unstable individual factor, such as effort or mood. Sandra Bem $(1967,1972)$ proposed that the bases for applying self-descriptive statements to one's own internal states do not differ significantly from those which others use to describe one's internal states. In sum, although much attribution research has historically emphasized the causes of success and failure in others, more recent research has focused on how people attribute causality with respect to their own behavior. 


\section{Contemporary Theories of the Self}

Early self theorists viewed the self as an organizing principle for perceptions of the individual's social world. Hall (1898), James (1915), and McDougall (1921) recognized the self as a cognitive or perceptual structure containing important emotional components. More recent self theorists (Epstein, 1973; Kelly, 1955; Rogers, 1951; Sarbin, 1962, as cited in Frazier, 1993) have proposed that the self is a dynamic structure which organizes, modifies, and integrates an individual's experiences. Whitbourne (1985, as cited in Frazier, 1993) viewed one's sense of self as the core of a person's life span experiences, motivational states, and action orientations. Kelly (1955, as cited in Frazier, 1993) argued that we actively hypothesize about our experiences in the world, generating self-concepts which take the form of "personal constructs" and dictate our future interactions. In cognitive psychology, Miller, Galanter, and Pribram (1960, as cited in Frazier, 1993) developed the information processing model which describes how the self-structure may organize representations of different aspects on one's social environment through cognitive interpretations and appraisals. Other contemporary theorists, such as Bandura, Baltes, and Bronfenbrenner, view the development of the self as a holistic process marked by intra-individual changes within the larger social context and focusing on the multi-directionality among psychological, biological, and environmental influences

When an individual processes self-relevant information, two co-existing self structures aid in the development of self-knowledge and ultimately contribute to the dynamic nature of the self-system, through one's self-concept and self-schemas (Frazier, 1993). The self-concept is primarily a social product shaped by sociocultural forces and 
which forms the cognitive component of the self, or one's conception of who one is, which differs from self-esteem, or the evaluative, affective component of the self (Frazier, 1993). According to Markus (Markus \& Hertzog, 1992, as cited in Frazier, 1993), the self-concept is active, forceful, and malleable and provides the framework used to render experience as meaningful. It serves to organize and lend meaning to one's thoughts, feelings, and actions, and it structures a person's values (Frazier, 1993). It has motivational weight and provides incentives, standards, plans, rules, and scripts for behavioral and interpretive frameworks for the consequences of behavior (Markus \& Herzog, 1992, as cited in Frazier, 1993).

Self-concept is responsive to environmental challenges (Greenwald \& Pratkanis, 1984; Kihlstrom, Cantor, Albright, Chew, Klein, \& Niedenthal, 1988, as cited in Frazier, 1993) and mediates and regulates both intrapersonal and interpersonal functioning. The self-concept is composed of one's cognitive assessment of the past, how one sees oneself currently, and what one believes is possible for the future (Frazier, 1993). Under the rubric of the self-concept are Markus's self-schemata, borrowed from cognitive psychology (Fodor, 1985; Neisser, 1986; Rumelhart \& Norman, 1978, as cited in Frazier, 1993). Schemata are constructs for actively selecting and subjectively interpreting information in our environment (Rybash, Hoyer, \& Roodin, 1986, as cited in Frazier, 1993). Markus (1977, as cited in Frazier, 1993) has argued that schemas exist specifically for the processing of self-knowledge and that these structures are cognitive generalizations about the self, responsible for organizing and guiding the processing of self-relevant information derived from the individual's social environment (Markus \& Hertzog, 1992; Markus \& Sentis, 1982, as cited in Frazier, 1993). Self-schemata include 
cognitive representations of the self based on past experiences, specific events, and ultimately represent and may predict patterns of an individual's behavior (Frazier, 1993).

A dialectical view of development takes change for granted rather than treating it as problematic and explainable only by delineating the physical maturational and external factors impinging on one's selfhood (Breytspraak, 1984). Klaus Riegel (1975, 1976, as cited in Breytspraak, 1984) focused on the simultaneous movement of persons in four dimensions: the inner-biological, the individual-psychological, the cultural-sociological, and the outer-physical; this perspective highlights the need to view the self in terms of continually changing circumstances which involve an interactive relationship between an individual and the environment.

Several theorists have proposed that the motive of self-consistency must be studied within the context of the situation; this movement has been called the contextualist perspective. Gergen $(1968,1977)$ was one of the first theorists to propose that people may demonstrate behaviors which conflict with their dispositional traits, based on the nature of the context and that the construct of the self must include the possibility of multiple selves, rather than a unitary self. Mischel $(1969,1971)$ has also studied the diversity of selves which result from our behaviors and proposed that, while our behavior tends to situation-specific, we nevertheless categorize and conceptualize ourselves in a fairly stable manner with dispositional terms and motives which extend beyond the information directly available from the observation of behavior. In sum, the motives toward self-esteem and self-consistency provide the basis for studying the self as an active and reactive force in continual interaction with changing contexts and different influential people in over the life span. The self-esteem motive is manifested in the 
tendency to distort reality in order to protect it by a variety of defense strategies; those who have high self-esteem may be most likely to use strategies which enhance it, whereas those with lower self-esteem may be more absorbed with maintaining a minimally satisfactory level (Breytspraak, 1984). Self-esteem largely results from experiencing a sense of competence and efficacy, but, when actual competence or efficacy is not experienced, it is important to seek a balance between our pretensions and our realistic skills (Breytspraak, 1984).

\section{Bandura's Social Cognitive Theory of the Self}

In his social cognitive theory of human development, Albert Bandura (1982) explains humans as active information processors and viewed the self as a guiding force for current behaviors and internal representations of what one wants to be and to become in the future. According to Bandura (1982), a person's goals serve as an internal driving force and potent catalyst for both short-term and long-term behavioral and cognitive efforts. Bandura's (1982) social cognitive theory hypothesized that an individual's sense of self-efficacy is either increased or decreased by both environmental variables and one's previous behaviors. This study applied Bandura's (1982) concept of self-efficacy to evaluate individuals' perceived ability to either achieve hoped-for possible selves or to avoid feared possible selves. This study also evaluated whether the use of social comparisons affects individuals' sense of self-efficacy, hypothesizing that comparing oneself to others' standards and expectations impacts one's sense of self-efficacy. Bandura's (1989) research has linked self-efficacy to self-regulatory processes, which are daily behaviors triggered by both external standards of evaluation and internal selfobservation and serve as an ongoing monitoring and evaluative force within the self. 
Bandura (1982) asserts that behaviors which measure up to one's internal standards are judged positively, while those which do not meet these standards are judged negatively. Bandura (1982) has supported the role of social comparisons in the development and maintenance of self-efficacy through his research findings that mastery experiences in comparison to others, modeling of others who have equal ability to either succeed or fail at a particular task, and attention given to a trusted person's encouraging words all increase one's sense of self-efficacy.

According to Bandura's (1977) self-efficacy theory, individuals develop domainspecific beliefs about their own abilities and characteristics which guide their behavior by determining what they try to achieve and how much effort they devote to their performance in a particular domain. According to Albert Bandura, self-efficacy is represented by a person's beliefs in his or her ability to succeed in a particular situation, and these beliefs are determinants of how a person approaches goals, tasks, and challenges in life (1994). Bandura (1977) initiated the study of self-efficacy as one of the most studied topics in the field of psychology. Bandura asserted that a strong sense of self-efficacy relates to one's ability to view challenging problems as tasks to be mastered, a deeper interest in and greater commitment to daily activities, and a buffer against setbacks and disappointments. Bandura (1992) also proposed that the growth of selfefficacy continues to evolve throughout life as people acquire new skills and experiences. Bandura's theory about self-efficacy and positive mental health outcomes is particularly relevant to the current study, which examined the impact of greater self-efficacy upon anxiety and depression. 
Another Bandurian (1977) concept, triadic reciprocal causation, explains the self as an ongoing, dynamic, and bidirectional interaction of behaviors, personal factors (such as thoughts and emotions), and environmental events. The triadic reciprocal causation model proposes that these three factors do not make equal contributions to the creation of the self but that the relative influence of behaviors, environment, and personal factors depends upon which factor is strongest at any particular moment (Bandura, 1989). Bandura (1989) also developed the concept of human agency to describe an individual's ability to organize, regulate, and enact behaviors which are expected to produce desirable consequences. According to Bandura (1989), human agency consists of intentionality, which is a proactive commitment to actions that may bring about desired outcomes, foresight in setting goals, self-reactiveness in monitoring one's progress toward fulfilling one's choices, and self-reflectiveness, which allows an individual to think about and evaluate one's motives, values, and life goals.

Baltes' Life Span Theory of the Self

Baltes' (1987) life span theory has been influential in understanding the developmental process as holistic and consisting of series of interactions between the individual and the larger cultural and historical context within which one's development occurs. Baltes' (1987) life span theory supports the unification of the historical split between continuity and discontinuity and between qualitative and quantitative change by viewing ontogenetic development as a lifelong process marked by both inter-individual differences and intra-individual changes. Level 1 involves biological and cultural influences, level 2 involves dynamics of gains and losses, level 3 involves 
metatheoretical propositions, level 4 involves selective optimization and compensation, and level 5 involves domain specific theories such as intelligence and traits of the self.

\section{Bronfenbrenner's Bioecological Theory of the Self}

Bronfenbrenner's (1998) bioecological theory views human development as a dynamic process involving the developing person, both immediate and generational environmental contexts, and specific time periods during which proximal events occur. The concept of "process" is key to Bronfenbrenner's (1998) bioecological theory, although the power of the following five types of processes varies according to person, environment, and time: (1) the person must engage in an activity to achieve development, (2) developmental effectiveness and complexity of an activity require occurrence on a regular basis over an extended period of time, (3) proximal processes are not unidirectional and require reciprocal exchange between the organism and environment, (4) proximal processes can involve people, objects, or symbols, and (5) developmental capacity increases in level and range over time. Bronfenbrenner (1998) conceptualizes the individual in terms of dispositional traits, bioecological resources (ability, knowledge, experience, and skills required for the effective functioning of proximal processes at any given stage of development), and demand characteristics, which either encourage or discourage positive reactions from the social environment. Bronfenbrenner's (1998) bioecological theory can be applied to the study of social comparison and gender roles in its emphasis upon the qualities of different proximal processes throughout our developmental path. According to Bronfenbrenner (1998), these proximal processes must take place on a fairly regular basis over a period of time but must also be marked by 
complexity, such as not just spending time with one's mother or father, but by the nature of activities and the related emotional components.

While the self has received attention throughout the history of both philosophy and psychology, contemporary theorists have placed a new level of emphasis upon the need to study the self as shaped by a constantly changing interactive process between the individual and one's social influences. Across the lifespan, the importance of others in shaping an individual's sense of self cannot be undermined, and modern contextualist and developmental systems theorists have focused on the interactive process between the self and important people, such as family, friends, and other role models, in one's social environment. Because the development of one's sense of self does not occur in a vacuum, the self must be studied in terms of one's sociocultural, historical, and developmental context. Therefore, the next section of this proposal will present the dominant theories about social comparison processes as they influence the formation of an individual's sense of current and future self.

The role of others in the developmental evolution of one's sense of self cannot be fully understood without examining social comparison processes. Social comparisons shape the development of one's sense of self, in terms of specific personality traits, values, opinions, behaviors, refinement of one's particular abilities, and evaluations of one's successes and failures. Since the 1990's, there has been a renewal of interest in the relationship between social comparisons and an individual's current self-concept (Suls \& Wheeler, 2000). The proposed study is significant in its exploration of the potential effects which social comparison targets and processes have upon an individual's perceived capability (evidenced by current behavioral choices and cognitive appraisals of 
the self) toward achieving a desired future self and avoiding a feared future self. Bandura's social cognitive theory relates directly to the research aims of the proposed study. Consistent with Bandura's theory, individuals evaluate their self-efficacy through comparisons to significant others and to social expectations and standards, and they develop and sustain self-regulatory behaviors which promote accomplishments and abilities perceived as better than those to whom they compare themselves or better than they have previously displayed. Bandura's concepts cannot be understood outside of social comparisons.

\section{Overview of Possible Selves}

Possible selves have been defined as the "future-oriented component" of a person's self-concept (Oyserman, Terry, \& Bybee, 2002) and as hypothetical images of what one hopes to become or what one fears becoming (Markus \& Nurius, 1986). Markus (1977) has conceptualized the self-concept as a system, rather than a unitary entity, of salient identities or self-schemas. These self-schemas are derived from past experiences and from one's place in the social structure, and they have evidenced a pervasive influence on how information about the self is processed (Markus \& Nurius, 1986). Selfschemas define past and present self, but they more importantly define future image of self, which can serve as an inner cognitive and emotional guiding force to act as a protective factor in the face of adverse life circumstances. Transitional periods are marked by distinct changes and growth in the self-system, and, similarly, in possible selves. Thus, possible selves provide an essential link between the self-concept and motivation, because they are the cognitive manifestations of a person's enduring goals, motives, fears, and threats (Markus \& Nurius, 1986), each person having a unique set of 
these cognitive manifestations. To fully understand one's possible selves is to examine one's working self-concept, which is a set of self-conceptions presently accessible in one's thoughts and memories and is a continually active, shifting array of available selfknowledge (Markus \& Nurius, 1986). Prior to Markus and Nurius' (1986) conceptualization of the possible self, Rogers (1951) identified the ideal self as what an individual believes he or she should be.

Possible selves have also been defined by Markus and Ruvolo (1989) as the elements of the self-schema, or self-representation, which are required for putting the self into action and which are more motivation effective when more elaborated. Previous research focused on the measurement of possible selves has either been content-based or balance-based (Oyserman \& Fryberg, 2000). Balance scores of both hoped-for and feared possible selves consists of a ratio of positive expectations to fears within the same content domain, such as academic or interpersonal, of possible selves (Oyserman \& Fryberg, 2000). Measures of possible selves have been in three main formats: (1) close-ended format yielding scores of both positive and negative possible selves across domains, (2) open-ended format content coded by domain, and (3) close-ended format focusing on a specific type of possible self (Oyserman \& Fryberg, 2000).

Possible selves formed during adolescence and young adulthood have been focused on academic success (Anderman, Anderman, \& Griesinger, 1999; Leondari, Syngollitou, \& Kiosseoglou, 1998; Oyserman, Gant, \& Ager, 1995), career exploration and occupational choice (Chalk, Meara, \& Day, 1994; Shepard \& Marshall, 1999), and delinquency (Oyserman \& Saltz, 1993; Stein, Roeser, \& Markus, 1998). Hooker, Fiese, Jenkins, Morfei, and Schwagler (1996) found that adults in their late twenties to early 
thirties, identified possible selves indicative of a transition to parenting roles. Hoped-for selves containing themes about starting a family, raising children, and learning to live with a marriage partner accounted for $73 \%$ of the sample of 228 men and women, and feared selves related to failure in these tasks accounted for $65 \%$ of the sample (Hooker et al., 2006). Outside of the family domain, the young adult age group also reported both hoped-for and feared possible selves related to starting a career, engaging in civic activities, finding a satisfying social group, and managing a home (Hooker et al., 2006). Research shows that parenting-related possible selves are strongly represented in young adults' possible selves and parallel the transition into this new role (Hooker et al., 1996). Current research has indicated that the most important hoped-for and feared possible selves among young adults involve goals related to education, career, family, and success (Arnett, 2000; Hooker, 1992; Oyserman, 1990a) and that family members are the most likely social comparison targets among this age group (Belle, 1998; Bronfenbrenner \& Morris, 1998; Furman \& Buhrmester, 1985; Levitt, Guacci-Franco, \& Levitt, 1993; Tucker, Barber, \& Eccles, 1997; 2001).

Possible Selves and Self-regulatory Processes

The concept of possible selves is an outgrowth of developmental systems theory (Ford \& Lerner, 1992; Hooker, 1999), which is a variant of control theory (Carver \& Scheier, 1982; see also Bandura, 1982; 1989). Control theory specifies the self-regulatory processes that determine the actions, plans, and behaviors brought to bear on possible selves. Control theory asserts that individuals engage in a comparison process in which they compare their current selves to their ideal selves. When discrepancies exist, they are motivated to change the self in order to minimize the discrepancy. Both possible selves 
and self-regulatory processes influence beliefs and behaviors on a day-to-day basis, in service of helping one become or avoid specific images of the self in the future. For example, a middle-aged adult returning to school for an advanced degree may face daily conflicts posed by challenging and time-consuming coursework, the stress of a full-time job, and the responsibilities of parenting and family. The ability to endure and master these conflicts may come from the promise of the increased status, prestige, and income that will come with the desired future career, and, thus, illustrate how possible selves work in conjunction with self-regulatory processes to influence development.

Self-regulation is demonstrated by cognitive choices and behavioral acts aimed at either achieving or avoiding one's possible selves. Self-regulation is an important motivating force and a source of internal control over one's environment. Immanuel Kant believed that to say that you ought to do something implies that you are able, but whenever we try to understand time, there comes a certain conception of what is important in life, of life's meaning, a direction in which we must travel, an aim. The present is forever slipping away, so the meaning of life is tied to moments. These moments must be a function of our goals, desires, and projections---all forms of selfregulation. Most of all, we value our intelligence and our morality which guide our selfregulatory behaviors. Self-regulatory behaviors create an internal locus of control which can serve as a protective factor in the face of adverse circumstances. Carstensen and Lockenhoff (2003) have brought attention to the important role of cognitive appraisal of past, present, and future events as a guiding force integral in maintaining a sense of wisdom and balance to one's self and to one's ability to engage in a dynamic process of self-reflection throughout adulthood. 
The link between possible selves and self-regulatory behaviors is a research area requiring more attention. We engage in daily future-oriented actions, such as adhering to a budget, following a nutrition plan, exercising, and completing necessary academic or work tasks, so that we can reach our desired goals and avoid our feared negative outcomes. Thus, our self-system directs our daily behaviors to maximize the possibility of achieving hoped-for possible selves and of avoiding or preventing feared possible selves. Research on possible selves and self-regulation has emphasized the psychological centrality of developmentally important issues during adolescence and young adulthood, but no research on possible selves has examined the role of others in the development of these future self-representations and goals.

\section{Possible Selves and Psychosocial Outcomes}

Possible selves have been correlated with positive psychosocial outcomes, such as control beliefs, well-being, and life satisfaction (Cross \& Markus, 1991; Frazier et al., 2007; Hooker, 1992; Hooker \& Kaus, 1992; 1994). It is suggested that social evaluations influence self-evaluation for both the present self and future possible selves, and, thus, directs subsequent behaviors. Social support is seen as influencing mental health outcomes through cognitive and emotional appraisal processes, which assign value and meaning to others' actions, to one's sense self, and to one's coping efforts.

\section{Social Comparisons and Formation of the Self}

Leon Festinger (1954) was the first examine the role of social comparison in an individual's self-development. Social comparison is the process by which people establish, maintain, refine, or embellish their self-concepts (Alicke, 1985). Social comparison processes are intrinsic in the way people learn about themselves, such as their 
characteristics and abilities, their beliefs and opinions, their behaviors and actions, and their successes and failures (Festinger, 1954a; Suls \& Willis, 1991; 2000; Wheeler \& Miyake, 1992). Social comparison processes include comparing the self to someone better off (i.e., upward comparison), to someone worse off (i.e., downward comparison), or to the self at another point in time (i.e., temporal comparison). Self-evaluations are part of the developmental process, according to Festinger (1954), because our self-knowledge may not match what others in our social environment see.

The general concept of social comparison has been explored by Aristotle in the Nichomachean Ethics (Suls \& Wheeler, 2000) and by Cooley (1902), James (1890), and Mead (1934). Early social psychological research provided evidence for the essential role of social comparison in self-evaluation. Sherif's (1936) work on conformity with the autokinetic phenomenon, Newcomb's Bennington College project, Asch's (1956) studies of independence and dependence in response to a unanimous majority, and Hyman's (1942) reference group concept all represent the importance of social comparisons with other people (Merton \& Kitt, 1950, as cited in Suls \& Wheeler, 2000). Festinger's (1942) first published research study showed that subjects would lower their aspirations if they found themselves above the group average and raise their aspirations if they scored below the group average, and, moreover, the status of the group made a difference.

The undergraduate students in Festinger's (1942) study raised their level of aspiration the most when they had scored below the high school students, and they lowered their level of aspiration the most when they had scored above the graduate students. The second major influence was the research on informal communication in small groups which Festinger and his colleagues initiated at the Research Center for 
Group Dynamics and which culminated in Festinger's (1950) theory that people in groups desire to attain uniformity of opinion either because group consensus provides confidence in one's opinion or because agreement was needed to coordinate group goals. Several experiments on group communication and rejection of opinion deviates (Back, 1951; Festinger, Schachter, \& Back, 1950; Festinger \& Thibaut, 1951; Kelley, 1951; Schachter, 1951; Thibaut, 1950) have supported Festinger's (1950) theory on informal communication, which was the precursor for his social comparison theory four years later.

Festinger's (1954) social comparison theory proposes that there is a drive within individuals to look to outside images in order to evaluate their own opinions and abilities. These images may be a reference to physical reality or a comparison to other people (Festinger, 1954). In his initial theory, Festinger (1954) hypothesized that there is an upward drive toward achieving greater abilities, but that there are non-social restraints which make it nearly impossible to change them and to cease comparison between one's self and others causes hostility and depreciation of opinions. Furthermore, Festinger (1954) proposed that those who are similar to an individual are particularly effective in generating accurate evaluations of abilities and opinions (Suls, Martin, \& Wheeler, 2002). Social comparison theory states that we seek to compare ourselves to others who we believe to be similar to ourselves, particularly to determine our own levels of success (Bessenoff, 2006).

Social comparison theory has been supported by the symbolic interactionism movement begun by Herbert Blumer (1969). Symbolic interactionism is based on the assumptions that (1) humans act toward things on the basis of the meanings they ascribe 
to those things, (2) the meaning of such things arises out of the social interaction one has with others and with the larger society, and (3) these meanings are handled in and modified through an interpretative process by the person in dealing with encountered things (Blumer, 1969). In sum, people interact with each other by interpreting or defining one another's actions, and it is the meaning of these actions, more than the literal actions themselves, which influence both our self-perceptions and our perceptions of others.

At the end of the 1980's, several summative statements were being made about social comparison processes. First, for accurate self-evaluation, people compare with similar others on related attributes, and, for self-enhancement, people compare with others who are worse off than themselves. Secondly, comparing with less fortunate others was found to be not the only way to increase one's self-esteem, because evidence emerged in support of high, rather than low, self-esteem as more likely to relate to benefits from downward social comparison. Taylor and Lobel (1989) then argued that social comparison processes can be served by different types of activity, such as the desire for information about others and a desire to affiliate with others. Rather than assume that these activities are interchangeable, Taylor and Lobel (1989) found suggestive evidence that downward social comparisons enhance one's self-perception, while upward social comparisons provide inspiration and information about how to improve, and that upward social comparisons can also be effective for persons experiencing threat.

Taylor and Lobel's (1989) research led to Wood's (1989) study on the role of self-improvement in social comparisons. A year later, an empirical paper by Buunk, Collins, Taylor, VanYperen, and Dakof (1990) entitled, “The Affective Consequences of 
Social Comparison: Either Direction Has Its Ups and Downs," proposed that social comparison can produce positive or negative feelings independent of direction. This study (Buunk et al., 1990) brought attention to the potential affective and cognitive benefits of both upward and downward social comparisons. In conclusion, while the emphasis from the 1950's through the mid-1970's was on accurate self-evaluation through social comparison and on upward social comparison, the 1980's brought a focus upon self-enhancement primarily through downward social comparison. Contemporary researchers are examining the possible mediating factors influencing both upward and downward social comparison.

There is a need for research examining the cognitive processes underlying social comparison (Buunk \& Gibbons, 1997). Although social comparison theory has been influenced by work on social cognition, only recently have research methods on social cognition been applied to the study of social comparison (Buunk \& Gibbons, 1997; Gibbons \& Gerrard, 1997; Goethals \& Darley, 1977). There is a need for greater research emphasis on the interplay between social comparison and social cognition (Buunk \& Gibbons, 1997). Social comparison has been hypothesized to assist individuals in determining their rank in social groups, assessing what others find attractive in them, and providing information on how they should change their behavior to obtain favorable outcomes (Gilbert, 1990; Gilbert, Price, \& Allan, 1995, as cited in Buunk \& Gibbons, 1997). Social comparison has also been correlated with depressed mood states, with results showing that depression is characterized by thoughts that are deprecatory and pessimistic with regard to the self (Weary \& Edwards, 1994, as cited in Buunk \& Gibbons, 1997), depressed individuals perceive themselves as incompetent, worthless, 
and critical of their own characteristics, indicating that they consider their own status as low (Hammen, 1997, as cited in Buunk \& Gibbons, 1997), and depressed individuals tend to feel that others are better off than they are, thus confirming their low social status (Albright \& Henderson, 1995, as cited in Buunk \& Gibbons, 1997). In sum, social comparison research has further to go in understanding the cognitive evaluations regarding differences and similarities, strengths and weaknesses, between oneself and others and relating these evaluations to their impact on mental health outcomes, general well-being, and sense of self.

The central tenet of social comparison research is that the self-concept is shaped by feedback from one's social comparison target (Alicke, 1985). Thus, one's impressions of social comparison targets cannot be viewed separately from the formative process of one's self-concept. The early history of social comparison research emphasized the comparisons which people select to evaluate their abilities and opinions about themselves and others, specifically whether people compare their performance outcomes by comparing themselves to superior or inferior others (Latane, 1966). The rank order paradigm was the most popular research design in early social comparison research and required study participants to learn their dispositional position on an ability test and then indicate their preference for viewing higher- or lower-ranked scores, with the general finding that people compare themselves with hypothetical others as well as with specific referents with whom they have frequent and significant interactions in their social environment (Alicke, 1985). In forming perceptions of others in our social environment, admitting that other people are morally, socially, intellectually, or physically superior may require downgrading perceptions about oneself, while acknowledging the 
incompetence of the people we outperform can negate the potential benefit of the comparison (Alicke, 1985).

According to Beach and Tesser's (2000) self-evaluation model (SEM), central to the self-evaluation process is the comparison of one's performance to others, especially those who are psychologically close, as opposed to those who are psychologically distant. Moreover, the importance of the comparison process is a direct result of the relevance of the performance domain to one's sense of self. The SEM model assumes that individuals are motivated to maintain a positive self-definition and that the performances of close others impacts one's self-definition (Beach \& Tesser, 2000). The particular impact, positive or negative, depends on the relevance of others to forming and maintaining one's self-evaluation (Beach \& Tesser, 2000). The SEM model suggests that the social consequences to self-esteem are amplified in the context of psychologically close others rather than distant others (Beach \& Tesser, 2000). Self-esteem can be viewed as an adaptation to group living and that feeling outperformed leads to changes in behavior or self-construal related to negative comparison (Beach \& Tesser, 2000). The self is gradually molded to find ways to make a unique or salient contribution to the larger group while simultaneously being molded to support the efforts of others to make important contributions (Beach \& Tesser, 2000). These findings suggest that significant others exert strong influence on one's aspects of identity and conceptions of the self (Beach \& Tesser, 2000). Taken together, this body of work stresses the importance of others in the self-evaluation process, the mechanisms through which others influence our self-evaluations (i.e., social comparison processes), and the importance of social 
comparisons to one's sense of achievement of psychologically central domains of self (Beach \& Tesser, 2000).

The dilemma is between accurately assessing others' abilities and characteristics and risking self-concept damage. Four moderators of social comparison target impressions are (1) the ambiguity of the social comparison target, (2) the importance of the comparison dimension (such as intellectual, physical, social status) used to shape the subject's self-concept, (3) the nature of the relationship between the subject and social comparison target, and (4) the subject's need for accuracy (Alicke, 1985). First, social comparison target ambiguity determines whether conditions are conducive for selfenhancement. For instance, objectively-based social comparisons, such as one's job status or salary, are relatively unambiguous and difficult to manipulate for selfenhancement purposes, while subjectively-based social comparisons, such as degree of honesty or integrity, can be quite ambiguous in determining one's sense of worth relative to others. Secondly, comparisons on central self-concept dimensions encourage motivationally-based revisions more than peripheral comparisons (Miller, 1984). Third, the social comparison target's closeness to the subject can affect how comparisons are cognitively construed, which has been demonstrated by the tendency for a person to distance oneself from or to derogate superior performers with whom one has frequent interaction (Tesser, 1988). Finally, the contrasting needs for self-esteem maintenance and accurate self-assessment which underlie the fundamental social comparison dilemma can instigate a cost-benefit analysis in which subjects weigh the benefits of personal advancement against the potential costs associated with a decline in one's perceived sense of self-worth (Alicke, 1985). 
Tajfel (1972) asserts that social comparison is central to social identity, defined as an individual's knowledge that he or she belongs to particular social groups and the accompanying emotional significance derived from group membership. Tajfel (1972) extended Festinger's (1954) theory of social comparison to propose that this process may be involved in almost all evaluations of one's opinions and abilities. Tajfel (1974) explains how groups and their members may pursue different strategies to protect or enhance positive distinctiveness and positive social identity. The choice of strategy is determined by a person's subjective understanding of the nature of relations between groups in terms of (1) the relative status of groups, (2) the stability of the status relations, (3) the legitimacy of the status relations, and (4) the permeability of intergroup boundaries. Social identity processes are associated with a self-enhancement motive which causes people to do whatever is contextually feasible to protect or enhance the valence of one's social identity, thus preserving one's self-esteem (Hogg, 2000). Thus, the self-evaluative penalty of lower-status group membership can be resolved by associating with the higher-status group (Hogg, 2000). In intergroup contexts, lowered self-esteem motivates people to identify with their own group and thus to display intergroup behaviors, and social identification elevates self-esteem (Abrams \& Hogg, 1988).

The relationship between self-esteem and identification may be influenced by a number of factors, such as the extremity of self-esteem, the degree to which people identify with the group, the extent to which groups and their members may feel under threat, and whether self-esteem is determined by individual or group membership (Abrams \& Hogg, 1988; Hogg \& Abrams, 1990, 1993; Hogg \& Mullin, 1999; Long \& 
Spears, 1997; Rubin \& Hewstone, 1998, as cited in Hogg, 2000). A body of social identity research supports the idea that, in intergroup contexts, social comparisons are governed by a striving for positive in-group distinctiveness.

Turner (1978) found that people made more extreme in-group favoring comparisons when groups with stable status relations were similar than when they were dissimilar and that, in intergroup contexts, increasing intergroup similarity motivates people to make comparisons that accentuate intergroup differences. Self-categorization theory (Turner, 1985; Turner, Hogg, Oakes, Reicher, \& Wetherell, 1987, as cited in Hogg, 2000) grew out of Tajfel's $(1972,1974)$ and Turner's (1978) social identity theory and proposes that self-categorization and social comparison processes are mutually dependent upon one another and that the self-categorization process constructs contextually relevant in-group and out-group prototypes which capture meaningful similarities within and differences between groups. Self-categorization theory has generated research on intragroup processes and intragroup differentiation, as well as the impact of these processes on one's self-concept (Hogg, 2000). In sum, people can relate to one another as unique individuals on an interpersonal level, as members of the same group, and as members of contrasting groups (Hogg, 2000).

\section{Upward Social Comparison Processes and the Self}

An extensive body of research has shown that individuals spontaneously make comparisons with others who are perceived as slightly better off than themselves (Lockwood, 2002). Favorable upward comparisons are potentially the most egoenhancing of all social comparisons. For instance, outperforming outstanding class members on a test is ego-enhancing to students of lesser ability. A natural consequence of 
such comparisons is to shift oneself upward toward and perhaps beyond the target. Other possibilities are to shift the target downward toward oneself or both shifts to occur simultaneously, such that the self is shifted upward and the target is shifted downward. The most desirable is an upward shift, because it represents the greatest self-concept gain relative to the target. Because favorable upward comparisons indicate that the comparer is unexpectedly superior to the target on the comparison dimension, such comparisons present an interesting dilemma in close personal relationships, particularly when interpersonal values are involved. An example involves one's parents, who have always proclaimed racial tolerance, discouraging interracial relationships. Because of their cognitive availability and emotional impact, negative expectancy violations may be expected to produce downward shifts in target evaluations.

Outperforming reputedly superior targets may also raise questions about the comparison's reliability, especially if the outperformance is extreme. Instead of adjusting their own or the target's status, people could instead question the likelihood of repeating the outperformance in similar circumstances. Although this tactic would be disadvantageous from a self-enhancement perspective, accuracy concerns sometimes override self-enhancement needs and lead people to seek further comparison data. One possible response to favorable but potentially unreliable upward comparisons is to handicap oneself in future comparisons. In the context of social comparison, stacking the deck against oneself provides a ready excuse for being outperformed. Self-handicapping research suggests that people will sabotage their future performances when they are uncertain about the basis of their initial successes and will construct obstacles to success when further comparisons with the target are inevitable and they are unconfident in 
repeating the outperformance (Berglas \& Jones, 1978; Higgins, Snyder, \& Berglas, 1990).

Tesser's $(1988,1991)$ self-evaluation maintenance (SEM) model provides the most thorough analysis of reactions to unfavorable upward social comparisons, which tend to create an often distressing self-reflection process. Tesser $(1988,1991)$ hypothesized in his self-evaluation maintenance (SEM) model that people find it more difficult to admit inferiority on personally relevant self-concept dimensions and that the degree to which target attributions are moderated by ego-related concerns depends on the degree to which the comparison dimension represents an essential aspect of one's identity. Beach and Tesser (2000) take the view that individuals are motivated to maintain positive feelings about the self, that this motivation creates a propensity toward favorable self feedback, and that comparisons to those who succeed oneself in ability or status, particularly those who are psychologically close to oneself, cause feelings of inferiority and a threat to one's self-evaluation.

\section{Lateral Social Comparison Processes and the Self}

The fundamental tenet of Festinger's (1954) original social comparison theory is that people prefer to compare their abilities with similar others and that these lateral comparisons are more informative for assessing abilities than comparisons with dissimilar others. Festinger (1954) believed that favorable lateral comparisons on focal attributes are less informative than favorable upward comparisons, in that knowing that you have outperformed someone who is similar to you in ability is less surprising than knowing that you have outperformed someone who is superior to you in ability. Lateral 
comparison successes may lead to a slight upward self-concept revision or to a slight downward adjustment of the partner (Buunk \& Gibbons, 2000).

\section{Downward Social Comparison Processes and the Self}

In general, the findings show a general pattern of downward comparison processes creating positive affect and upward comparisons creating negative affect (Suls \& Wheeler, 2000; Brickman \& Bulman, 1977; Buunk, Collins, Taylor, VanYperen, \& Dakof, 1990; Taylor \& Lobel, 1989). Findings also consistently show the influence of social comparison processes on self-esteem and self-evaluations (Collins, 1996). The self-evaluation maintenance (SEM) model has been put forward to articulate the processes and conditions under which individuals maintain positive feelings about the self (Beach \& Tesser, 1995; 2000). While downward social comparisons have been linked with improved self-confidence and outlook for one's future (Gilbert, Giesler, \& Morris, 1995; Pelham \& Wachsmuth, 1995, as cited in Kemmelmeier \& Oyserman, 2001), a downward self-adjustment, and, thus, lowered self-confidence, may be likely when the other is viewed as similar to the self and one feels a sense of connection with the other (Buunk \& Ybema, 1997, as cited in Kemmelmeier \& Oyserman, 2001). Trope (1986) added that that taking the failure of another person into account may provide diagnostic information about potential dangers facing the self, and, thus, may initiate a realistic reassessment and downward adjustment of one's own chances of success and failure.

Outperforming inferior targets is generally uninformative about either one's own capabilities or those of the other. Comparing favorably to targets who are expected to be inferior may lead to a slight downward adjustment of the target, a slight upward self- 
adjustment, or a simultaneous upward movement of the self and downward movement of the target. Favorable downward comparisons are likely to lead subjects to exaggerate the targets' abilities and may in some circumstances even improve self-evaluations (Alicke, LoSchiavo, Zerbst, \& Zhang, 1997). Downward comparisons are most informative when the margin of outperformance is greater or less than expected; engaging in a close competition with a reputedly inferior performer may lead to a diminished perception of one's abilities or to an enhanced view of the target (Suls \& Wheeler, 2000; Buunk \& Gibbons, 2000). Self-enhancement perspectives predict target aggrandizement, although when accuracy concerns predominance, people may adjust their ability downward as a result of favorable, but unexpectedly close, comparisons. An unexplored implication of self-enhancement perspectives is that subjects may elevate their self-views via nondiagnostic downward comparisons. For example, although there is little to be learned from lifting heavier weights than a much smaller person, the superior performer may undercorrect for this difference and thereby exaggerate one's weightlifting ability. People may even search actively for nondiagnostic downward comparisons. An example is provided by older children who interact and compare with younger ones to inflate their perceived abilities. In such cases, older children may discount their advantage on related attributes or exaggerate the younger children's competence on the focal dimension, thus enhancing the comparison's value.

Some researchers have found evidence that the impact of upward and downward social comparison processes are to some degree subject to gender-specific differences in underlying structure of one's self-concept. Kemmelmeier and Oyserman (2001) found that men and women differ in how effectively they can counteract the implications of 
downward social comparisons. and that gendered responses to downward social comparisons are at least in part driven by a culturally normative focus on dispositional information prevalent in the West. Some studies have suggested that these comparisons may be differentially activated based on perceptions of threat and/or vulnerability (Aspinwall \& Taylor, 1993; Wood \& VanderZee, 1997). Downward social comparisons have been found to have a self-enhancing impact when an individual is dealing with a threat and feels less similar to the social comparison target (Lockwood \& Kunda, 1997; Taylor \& Lobel, 1989; Wills, 1981).

In sum, the direction of social comparison processes warrants further study as it relates to young adults' self-regulatory behaviors toward achieving their hoped-for possible selves. Downward social comparisons have been correlated with feelings of superiority (Wills, 1981). However, Festinger (1954) has argued that there is a unidirectional tendency toward upward social comparisons, and Collins (1996) has proposed that upward social comparisons serve several important functions, such as improving self-esteem, providing motivation and inspiration for achieving goals, and providing specific information for achieving goals. The proposed study will evaluate whether young adults tend to use social comparison targets in developing their hoped-for possible selves, whether the gender of their social comparison target influences the domains of their hoped-for possible selves, whether they make more upward, downward, or lateral social comparisons in developing their hoped-for possible selves, and whether the direction of their social comparison processes (upward, downward, or lateral) correlates with self-regulatory processes (self-efficacy and outcome expectancy) in achieving their hoped-for possible selves. 


\section{Gender Schema Theory and the Self}

Gender roles are "socially and culturally defined prescriptions and beliefs about the behavior and emotions of men and women" (Anselmi and Law 1998, p. 195). Many theorists believe that perceived gender roles form the bases for the development of gender identity. Prominent psychological theories of gender role and gender identity development include evolutionary theory (Buss 1995; Shields 1975), object-relations theory (Chodorow 1989), gender schema theory (Bem 1981, 1993) and social role theory (Eagly 1987). Internal discomfort and confusion can result from the development of possible selves which conflict with traditional expectations about gender roles or behaviors or which attempt to combine both masculine and feminine gender roles or behaviors. Traditional gender role identification is still prevalent in adolescence in many cultures (Brose, 2000), but may be more so in the Hispanic culture (Goodenow and Espin, 1993; Reid and Bing, 2000). Within a traditional Hispanic culture, the father is the breadwinner, while the mother is the homemaker and caregiver. When thinking of hopedfor possible selves, young women shaped their future self-concepts with their mothers as role models, while young men had role models in their fathers (Frazier, Montgomery, Hinton, Perez, Barreto, and Jauregui, 2003).

Gender schema theory (Bem 1981) focuses on the role of cognitive organization in addition to socialization. Bem's theory postulates that children learn how their cultures and/or societies define the roles of men and women and then internalize this knowledge as a gender schema, or unchallenged core belief. The gender schema is then used to organize subsequent experiences (Bem 1993). Children's perceptions of men and women are thus an interaction between their gender schemas and their experiences. Eventually, 
children will incorporate their own self-concepts into their gender schema and will assume the traits and behaviors that they deem suitable for their gender. Social schema theory builds on and uses terminology from schema theory in cognitive psychology, which describes how concepts from the external world are represented and categorized in the brain.

A review of literature on possible selves and gender differences indicates that females are more likely than males to incorporate the influences of others in forming possible selves and also in determining their sense of self-worth (Knox, 2006). Nevertheless, several studies have found significant influences of gender and sex roles on possible selves (Frazier, Montgomery, Barreto, and Perez, 2003; Hooker, Fiese, Jenkins, Morfei, and Schwagler, 1996; Morfei and Hooker, 1997). However, a caution must be noted in making such a gender-based assumption about possible selves, because of the still-emerging field of research regarding the impact of gender on one's conceptualized future possible selves (Knox, 2006).

The developmental path and resulting content of possible selves may differ by gender, and these differences may be relevant to gender differences in self-concept, selfesteem, and other aspects of positive functioning (Knox, 2006). Cross and Markus (1991) have found that significant discrepancies between hoped-for possible selves and actual selves, which can include discrepancies between gender role expectations and actual behaviors, relate to decreased reported levels of life satisfaction and self-esteem. The feminine ideal is quite different from the socialized masculine ideal in American culture. A model by Jordan, Kaplan, Miller, Stiver, \& Surrey (1991) compare traditionally socialized male traits of autonomy and individuation with female traits of 
interdependence and emotional connections with others. In other words, self-esteem in females is frequently dependent upon the success of interpersonal relationships, while self-esteem in males is determined by independence and a sense of instrumentality. Current research on gender roles and possible selves is aimed at exploring possible "blurring" of lines between what is means to be male or female (Knox, 2006). For instance, females are increasingly entering careers which have been traditionally considered "masculine" careers, such as becoming engineers, scientists, and physicians (Knox, 2006). In the field of possible selves research, the gradual evolution away from traditional gender role expectations indicates that females' possible selves may increasingly become less oriented toward family and interpersonal relationships and more oriented toward a future concept of assertiveness and self-sufficiency (Knox, 2006).

Purpose of the Study

My study contributes to the existing literature on social comparisons, gender roles, self-regulation, and mental health of young adults. Findings from the present study can contribute to prevention and intervention programs for high school and college students. My study also increases understanding of the important of young adults' sense of gender identity, as well as the pivotal role of others in helping young adults to form future goals. The study explored the motivational force of self-regulatory processes toward achieving one's goals and as a buffer against negative mental health outcomes among young adults.

Research Question 1:

Do differences in the gender of one's social comparison target correlate with differences in the domains of hoped-for possible selves identified by young adults? 
Hypothesis 1: The gender of one's social comparison target will significantly correlate with differences in the domains of hoped-for possible selves identified by young adults.

\section{Research Question 2a:}

Does the importance of directional social comparison processes (upward, downward, or lateral) correlate with the self-efficacy identified by young adults toward achieving their hoped-for possible selves?

Hypothesis 2a: Importance of directional social comparison processes (upward, downward, or lateral) will significantly correlate with the self-efficacy of young adults toward achieving their hoped-for possible selves.

\section{Research Question 2b:}

Does the importance of directional social comparison processes (upward, downward, or lateral) correlate with the outcome expectancy identified by young adults toward achieving their hoped-for possible selves?

Hypothesis 2b: Importance of directional social comparison processes (upward, downward, or lateral) will significantly correlate with the outcome expectancy of young adults toward achieving their hoped-for possible selves.

Research Question 3a:

Does gender role identification correlate with self-efficacy toward achieving hoped-for possible selves among young adults?

Hypothesis 3a: Gender role identification will significantly positively correlate with self-efficacy toward achieving hoped-for possible selves among young adults. 


\section{Research Question 3b:}

Does gender role identification correlate with outcome expectancy toward achieving hoped-for possible selves among young adults?

Hypothesis 3 b: Gender role identification will significantly positively correlate with outcome expectancy toward achieving hoped-for possible selves among young adults.

\section{Research Question 4a:}

Does the self-efficacy of young adults toward achieving their hoped-for possible selves correlate with depressive symptoms?

Hypothesis 4a: The self-efficacy of young adults toward achieving their hoped-for possible selves will significantly negatively correlate with depressive symptoms.

\section{Research Question 4b:}

Does the outcome expectancy of young adults toward achieving their hoped-for possible selves correlate with depressive symptoms?

Hypothesis $4 \mathrm{~b}$ : The outcome expectancy of young adults toward achieving their hoped-for possible selves will significantly negatively correlate with depressive symptoms.

\section{Research Question 5a:}

Does the self-efficacy of young adults toward achieving their hoped-for possible selves correlate with anxiety symptoms?

Hypothesis 5a: The self-efficacy of young adults toward achieving their hoped-for possible selves will significantly negatively correlate with anxiety symptoms. 


\section{Research Question 5b:}

Does the outcome expectancy of young adults toward achieving their hoped-for possible selves correlate with anxiety symptoms?

Hypothesis 5b: The outcome expectancy of young adults toward achieving their hoped-for possible selves will significantly negatively correlate with anxiety symptoms.

Research Question 6a:

Is traditional gender role identification among young adults different for females and males?

Hypothesis 6a: Traditional gender role identification among young adults will be significantly different between males and females.

Research Question 6b:

Is the direction of social comparison processes (upward or downward) used by young adults significantly different males and females?

Hypothesis 6b: The direction of social comparison processes (upward or downward) used by young adults will be significantly different for males and females.

Research Question 6c:

Are the self-regulatory processes (self-efficacy and outcome expectancy) of young adults significantly different for males and females?

Hypothesis 6c: The self-regulatory processes (self-efficacy and outcome expectancy) of young adults will be significantly different for males and females.

Research Question 6d:

Are mental health outcomes (depression, state anxiety, and trait anxiety) of young adults significantly different for males and females? 
Hypothesis 6d: Mental health outcomes (depression, state anxiety, and trait anxiety) of young adults will be significantly different for males and females. 


\section{METHODOLOGY}

\section{Participants}

One hundred and sixty-four $(\mathrm{n}=164)$ young adults between the ages of 17 and 30 $(\mathrm{M}=19.8, \mathrm{SD}=2.6)$ comprised the sample in this study. Sixty-one percent of the respondents were female, $95 \%$ of the respondents were single, $92 \%$ of the respondents were pursuing their Bachelor's degree, and $39 \%$ of the respondents were working while attending college. The sample was comprised of 7.3\% African Americans, 3.7\% Asians, 67.7\% Hispanics, $1.2 \%$ West Indians, 12.2\% White Non-Hispanics, and 7.9\% Other Ethnicity. Archival data for this sample were used in the study.

\section{Procedure}

All subjects were recruited from Introductory Psychology courses at Florida International University and were given course credit for study participation, which was voluntary. Trained research assistants described the possible selves protocol and led the participants through the study procedures.

\section{Measures}

The Possible Selves Interview. Possible selves were assessed in this study using an interview format modeled from the Cross and Markus Possible Selves Questionnaire (PSQ; 1991). Participants were introduced to the concept of possible selves when the interviewer read the following instructions:

"This part of the questionnaire addresses how you see yourself in the future. We all think of our futures to some extent. When doing so, we usually think about the kinds of experiences that are in store for us and the kinds of people we might possibly become. Sometimes, we think about what we hope to become in the 
future, which is our 'hoped-for possible self.' Some hoped-for possible selves seem quite likely, such as becoming a homeowner. Other future selves seem quite unlikely yet still possible, such as winning the lottery. Our current actions are not possible selves but are usually part of a possible self. Please take a few minutes to think about all of your hoped-for possible selves. You may have just a few, or you may have many."

Participants were asked to generate their own hoped-for possible selves, as many as possible. The interviewer recorded the selves as they were generated and then read them back to the participant. Participants were then asked to rank these hoped-for possible selves in order of importance, and the most important three hoped-for possible selves were discussed further. For each of the three most important hoped-for possible selves, participants were asked were asked to give a detailed description of the self (to get an idea what the vision looks like to the individual) and why it is important. The participants were then asked to describe the activities and behaviors (if any) in which they engage on a daily basis to ensure that each hoped-for possible self will become a reality in the future, and what, if any, obstacles or challenges they face in achieving this hoped-for possible self. They were then asked to identify the catalyst for developing this hoped-for possible self (i.e., was it generated by an experience or life event, some sort of epiphany, the influence of others' suggestions, etc.). Finally, they were asked a series of four questions which assessed their self-regulatory processes using a seven-point Likert scale. These questions provided quantitative data regarding the distance of one's hopedfor possible self ("How much does this self describe you now?), centrality ("How important is this self to your overall self-concept?"), self-efficacy for achieving one's 
hoped-for possible self (“How capable do you feel of achieving this self in the future?"), and outcome expectancy for achieving one's hoped-for possible self ("How likely do you think it is that you will actually achieve this self in the future?"). The process was repeated for each of the three most important hoped-for possible selves. After the hopedfor possible selves were completed, this process was repeated to assess the respondents' feared possible selves with the questions phrased to represent selves which the individual wants to avoid in the future.

The qualitative data from this measure were coded following Frazier and Hooker's (2006) coding scheme. Possible selves were coded into 18 categories representing salient domains of the self (i.e., family, health, leisure, independence, education, success, etc.). In order to establish inter-rater reliability, the Principal Investigator coded all data, and a Research Assistant (blind to the hypotheses being tested) then coded all data. Inter-rater reliability across all participants and all domains of possible selves was 94\% (Frazier, Montgomery, Hinton, Perez, Barreto, \& Jauregui, 2003).

Social comparison processes. A series of questions designed to gather qualitative and quantitative information regarding social comparison targets and processes were modeled on the Rochester Social Comparison Record (Wheeler \& Miyake, 1992) and used in this study's The Possible Selves Interview (Frazier, Montgomery, Hinton, Perez, Barreto, \& Jauregui, 2003). The first question asks subjects: “Thinking back to when you first decided that this hoped-for/feared self was an important goal for the future, can you identify an event, a personal realization, another person, or a particular influence that caused you to develop this self?" After generating a detailed description of this 
event/influence, subjects were asked if, when thinking about this possible self, they compared themselves to another person or to themselves at another point in time. If they answered "yes," they were provided with a list of potential social comparison targets (including the self) from which to choose and were asked to indicate the sex of the social comparison target. Subjects then answered nine questions designed to determine the degree of upward, downward, and temporal social comparison processes made with the target and two questions designed to assess competitiveness with and the degree of encouragement from the social comparison target.

Answers to the open-ended question regarding the initiating event for the development of the possible self were qualitatively coded into categories representing life turning points and the social influences involved in those turning points. An individual's social comparison target will be identified through one's response to the question "To whom do you compare yourself?" The possible responses are: (1) yourself at another point in time, (2) an acquaintance, (3) an ordinary friend, (4) a family member, (5) a famous person, (6) a close friend, (7) an imaginary person, (8) a stranger, and (9) other. The gender of one's social comparison target will be identified through one's response to the question "What sex is the person to whom you compare yourself?" The importance of one's social comparison target will be evaluated through one's response to the statements "He/she is my role model" and "He/she has been encouraging me to achieve my hopedfor self, and I don't want to disappoint him/her." Upward social comparison processes will be evaluated through one's responses, on a 7-point Likert scale, to the statement "He/she has achieved what I want to achieve." Downward social comparison processes will be evaluated through one's responses, on a 7-point Likert scale, to the statements, 
"He/she is not doing as well as I am at achieving this goal-so, compared to him/her, I am doing well," and "Comparing myself to someone less accomplished makes me feel better about myself."

Gender roles. A modified version of the Bem Sex Role Inventory (BSRI; Bem, 1974) was used to evaluate traditional gender roles. Using the adjectives found in the BSRI, 47 statements were constructed, and subjects were instructed to determine whether each statement was a true description of themselves. A Likert-type scale was constructed to allow subjects to report whether a statement was "never true of me (1)" to "always true of me (6)." Statements represented masculine sex role identification, feminine sex role identification, and androgyny. Respondents receive both masculinity and femininity scores based on the mean of the responses to masculine and feminine items, respectively. Cronbach alphas, calculated for masculinity and femininity, of .89 and .87 , previously reported by Bem (1981).

The Bem Sex Role Inventory (BSRI; 1977) was designed for conducting empirical research on psychological androgyny. The BSRI measures the extent to which respondents spontaneously sort self-relevant information into distinct masculine and feminine categories (Bem, 1977). The BSRI (Bem, 1977) contains sixty personality characteristics: twenty of the characteristics are stereotypically feminine (e.g., affectionate, gentle, understanding, sensitive to the needs of others) and twenty are stereotypically masculine (e.g., ambitious, self-reliant, independent, assertive). The BSRI also contains twenty filler items (e.g., truthful, happy, conceited). The BSRI (Bem, 1977) includes twenty feminine characteristics, twenty masculine and twenty neutral. The individual rates themselves as possessing the characteristic on a scale from one to seven, 
including never or almost never true to always or almost always true. When averaged, the median score is 4.5. Anyone above this is seen as possessing feminine or masculine traits. Unlike any other tests the individual may score high on both the feminine and masculine scales because they are scored separately. If this happens they are seen as androgynous, applying appropriate characteristics when necessary. If the scores are below the median of 4.5 on both the feminine and masculine characteristics, they are seen as undifferentiated (Bem, 1977). Along with the belief that masculinity and femininity are separate, Bem also believed androgynous individuals who possessed both masculine and feminine traits were "truly effective and well-functioning" (Bem, 1990, 33).

Anxiety. A modified version of the 40-item State-Trait Anxiety Inventory: SelfEvaluation Questionnaire (Spielberger, Gorsuch, Lushene, Vagg, \& Jacobs, 1983) was used to assess the degree of anxiety-provoking perceptions which subjects perceived in the present and as a function of their personalities. The Likert-type scale is composed of 20 questions representing state anxiety and 20 questions representing trait anxiety. Answer choices range from 1 to 4 , with higher scores indicating greater anxiety. The means on each subscale in the Frazier et al. (2003) study were: state anxiety $=39.26$ (range from 20 to 76 ) and trait anxiety $=39.27$ (range from 20 to 68). Cronbach's alphas in the Frazier et al. (2003) were .85 and.85, respectively.

Depression. Negative affect was assessed using the Center for Epidemiologic Studies Depression Scale (CES-D; Radloff, 1977). The measure is designed to assess the affective components of depression in a general population. The CES-D (Radloff, 1977) is a 20 -item Likert-type scale which asks subjects to report how often they have felt or behaved a particular way during the past week. Items on the CES-D (Radloff, 1977) refer 
to symptoms of depression (i.e., "I had trouble keeping my mind on what I was doing."). Each item has a 0 to 3 response scale, and, after item reversals and summing item scores (range of 0 to 60 ), higher scores indicate a greater level of depression. Scores of 16 or more are commonly indicative of depression or the equivalent of experiencing six symptoms over a period of one week (Radloff, 1977). The mean for depressed affect in the Frazier et al. (2003) sample was 15.9 (range of 0 to $50, \mathrm{SD}=10.6$ ), indicating that this sample was experiencing some clinically relevant symptoms of depression. Cronbach's alpha for this scale was .86 (Frazier et al., 2003).

Demographic data. Demographic information was collected for each participant, including age, gender, ethnicity, education level, and marital status.

\section{Analytic Strategy}

The present study analyzed archival data collected from administering the following measures: Possible Selves Inventory (Frazier, 2000), Bem Sex Role Inventory (Bem, 1977), State-Trait Anxiety Scale (Spielberger, Gorsuch, \& Lushene, 1983), and the Center for Epidemiologic Studies Depression Scale (CES-D; Radloff, 1977). Frequency distributions and cross-tabulations examined the qualitative variables in this study. Pearson correlations and regression analyses examined the linear relationship between quantitative variables in the current study. Multivariate analyses of variance (MANOVA) were used to examine between group differences in domains of hoped-for possible selves, direction of social comparison processes, self-regulatory processes, and mental health outcomes. The quantitative variables were: strength of gender role identification, direction of social comparison processes, strength of self-efficacy, strength of outcome expectancy, level of depression, level of state anxiety, and level of trait anxiety. 
For hypothesis one, cross tabulations and a chi-square test were used to examine the frequency of gender (male versus female) of one's social comparison target by the five domains of hoped-for possible selves answered most frequently. Post-hoc chi-square tests using the Holm's sequential Bonferroni procedure were then implemented since the chisquare test was significant. For hypotheses $2 \mathrm{a}$ and $2 \mathrm{~b}$, Pearson correlations and multiple regression analyses were used to measure the relationship between the importance of the direction of young adults' social comparison processes (upward and downward) and strength of self-regulatory processes (self-efficacy and outcome expectancy) toward achieving hoped-for possible selves. For hypotheses $3 \mathrm{a}$ and $3 \mathrm{~b}$, Pearson correlations and multiple regression analyses were used to measure the relationship between young adults' strength of gender role identification (masculine and feminine) and strength of selfregulatory processes (self-efficacy and outcome expectancy) toward achieving hoped-for possible selves.

For hypotheses $4 \mathrm{a}$ and $4 \mathrm{~b}$, Pearson correlations and multiple regression analyses were used to measure the relationship between young adults' strength of self-regulatory processes (self-efficacy and outcome expectancy) toward achieving hoped-for possible selves and depressive symptoms. For hypotheses $5 \mathrm{a}$ and $5 \mathrm{~b}$, Pearson correlations and multiple regression analyses were used to measure the relationship between young adults' strength of self-regulatory processes (self-efficacy and outcome expectancy) and anxiety symptoms. For hypothesis 6a, a multivariate analysis of variance (MANOVA) was used to evaluate whether there was a statistically significant difference between females and males in the 5 domains of hoped-for possible selves. For hypotheses $6 \mathrm{~b}-6 \mathrm{~d}$, a multiple regression analysis was used to evaluate whether there was a statistically significant 
difference between females and males in the direction of social comparison processes, gender role identification, self-efficacy, outcome expectancy, depression, and anxiety. 


\section{RESULTS}

Herein, I present the findings for both quantitative and qualitative data. Although qualitative data collection was not originally part of the proposed methodology, the small sample size $(\mathrm{n}=110)$ called for a mixed-methods analytical approach to better explore the relationship between the independent and dependent variables. The quantitative analysis will be presented first, followed by the qualitative findings. In addition, results for each of the research questions will be discussed individually.

The IBM SPSS software (v.19) was used to analyze the quantitative data.

\section{Demographic Characteristics}

Table 1 summarizes the frequency distribution for the demographic variables represented in my study. Young adults, ranging in ages from 17 to 22, represented the majority (89.6\%) of subjects in this study, with $10.4 \%$ comprising the 23 to 30 age group. Since my study was targeted toward development during young adulthood, this is a strength within the sample. More females (61.6\%) were represented in this study, compared to males $(38.4 \%)$. Regarding ethnic groups, the majority of subjects in this study (67.7\%) were Hispanic, with White Caucasians being much less represented (12.2\%), followed by Other ethnic groups (7.9\%), African-Americans (7.3\%), Asians (3.7\%), and West Indians (1.2\%). Regarding marital status, $96.8 \%$ of the subjects were never married. The majority of subjects in this study (72\%) were high school graduates, with $22 \%$ having some college.

\section{Correlation Findings}


$\underline{\text { Research Question 1: Do differences in the gender of one's social comparison }}$ $\underline{\text { target correlate with differences in the domains of hoped-for possible selves identified by }}$ young adults?

Table 2 presents the results of the distribution of gender of social comparison target for each of the five major domains of hoped-for possible selves. Cross-tabulation results were significant, $\mathrm{X}^{2}(4, N=110)=14.16, p<.007$, indicating that the gender of social comparison target distribution differed significantly between the Family domain of hoped-for possible selves and three domains of Abilities/Education, Success, and Occupation, $p<.05$. Eighty three percent $(83.3 \%)$ who chose the Family domain compared themselves to a female social comparison target, while only $33 \%$ of those who chose the Abilities/Education domain, 38\% of those who chose the Success domain, and $47 \%$ of those who chose the Occupation domain used a female social comparison target. On the other hand, $67 \%$ of those who chose Abilities/Education, $63 \%$ of those who chose Success, and $53 \%$ of those who chose Occupation used a male social comparison target, compared to only $17 \%$ of those who chose Family.

Research Question 2: Does the importance of directional social comparison processes (upward, downward, or lateral) correlate with the self-regulatory processes identified by young adults toward achieving their hoped-for possible selves?

Table 3 presents the Pearson correlation results for direction of social comparison processes (upward or downward) by self-efficacy and by outcome expectancy. There was no significant correlation found between self-efficacy and downward social comparison processes used by young adults in creating their hoped-for possible selves $(r=-.124, p>$ .10) or between self-efficacy and upward social comparison processes used by young 
adults in creating their hoped-for possible selves $(r=-.117, p>.10)$. There was also no significant correlation found between outcome expectancy and downward social comparison processes used by young adults in creating their hoped-for possible selves $(r$ $=-.128, p>.10$ ), but there was a marginally significant correlation between outcome expectancy and upward social comparison processes used by young adults in creating their hoped-for possible selves $(r=-.138, p<.10)$. The result does not show support for the hypothesis that differences in the direction of young adults' social comparison processes significantly relate to differences in the self-efficacy and outcome expectancy identified by young adults toward achieving their hoped-for possible selves.

Research Question 3: Does gender role identification correlate with selfregulatory processes of young adults toward achieving hoped-for possible selves?

Table 4 presents the Pearson correlation results for the relationship between gender role identification and self-regulatory processes (self-efficacy and outcome expectancy). The results indicated that masculine gender role identification positively correlated with self-efficacy $(r=.162, p<.05)$ and that feminine gender role identification positively correlated with both self- efficacy $(r=.154, p<.05)$ and outcome expectancy $(r=.212, p<.01)$. Higher scores on the BSRI masculine gender role identification were associated with greater self-efficacy identified by young adults toward achieving their hoped-for possible selves. Similarly, higher scores on the BSRI feminine gender role identification were associated with greater self-efficacy and greater outcome expectancy. This shows support for the hypothesis that differences in one's traditional gender role identification significantly relate to differences in the self-efficacy and 
outcome expectancy identified by young adults toward achieving their hoped-for possible selves.

$\underline{\text { Research Questions } 4 \text { and 5: Do self-regulatory processes of young adults toward }}$ achieving their hoped-for possible selves correlate with mental health outcomes (depression and anxiety)?

Table 5 presents the Pearson correlation results which showed a significant negative correlation between self-efficacy and state anxiety $(r=-.329, p<.01)$ and between self-efficacy and trait anxiety $(r=-.358, p<.01)$. These results also showed a significant negative correlation between outcome expectancy and trait anxiety $(r=-.213$, $p<.01$ ), and a marginally significant correlation between outcome expectancy and state anxiety $(r=-.138, p<.10)$. Among respondents in this study, a greater level of selfefficacy toward achieving one's hoped-for possible selves was associated with a lower level of reported state anxiety symptoms and a lower level of reported trait anxiety symptoms. Similarly, a higher level of outcome expectancy was associated with a lower level of trait anxiety symptoms. Table 5 also presents the Pearson correlation results which showed a significant negative correlation between self-efficacy and depression $(r=$ $-.259, p<.01)$. Among all respondents in this study, a greater level of self-efficacy toward achieving one's hoped-for possible selves was associated with a lower level of reported depressive symptoms. Level of outcome expectancy toward achieving one's hoped-for possible selves was not correlated with one's level of reported depressive symptoms. These results support hypotheses 4 and 5 that self-efficacy and outcome expectancy of young adults toward achieving their hoped-for possible selves significantly correlate with positive mental health outcomes. 
To address Research Questions 2 through 5 simultaneously, two regression analyses were carried out on self-efficacy and outcome expectancy as dependent variables. Self-efficacy was regressed on BSRI gender role identification, direction of social comparison processes, state-trait anxiety, and depression, controlling for age, gender, Hispanic versus non-Hispanic ethnicity, and educational level. Table 6 shows that the full regression model was significant, $R^{2}=22.1 \%, F(12,140)=3.32, p<.001$. Twenty-two percent of the variability of self-efficacy was explained by this model. After controlling for the independent demographic variables of age, gender, Hispanic versus non-Hispanic ethnicity, and education level, the variables of gender role identification, direction of social comparison processes, state-trait anxiety, and depression explained an additional $19.4 \%$ of the variability, $F(8,140)=4.36, p<.001$. Higher self-efficacy was associated with lower trait anxiety, $\beta=-.35, p=.01$, and being older, $\beta=.22, p<.05$.

In the second regression, outcome expectancy was regressed on BSRI gender role identification, direction of social comparison processes, state-trait anxiety, and depression, controlling for age, gender, Hispanic versus non-Hispanic ethnicity, and educational level. Table 7 shows that the full regression model was significant, $R^{2}=$ $15.4 \%, F(12,140)=2.12, p<.05$. Fifteen percent of the variability of outcome expectancy was explained by this model. After controlling for the independent demographic variables of age, gender, Hispanic versus non-Hispanic ethnicity, and education level, the variables of gender role identification, direction of social comparison processes, state-trait anxiety, and depression explained an additional $11.9 \%$ of the variability, $F(8,140)=2.47, p<.05$. Higher outcome expectancy was associated with lower trait anxiety, $\beta=-.31, p<.05$ and being older, $\beta=.26, p<.05$. Marginally 
significant results indicated that higher outcome expectancy was associated with those who responded that upward social comparisons, $\beta=-.14, p<.10$, and downward social comparisons, $\beta=-.14, p<.10$, were more important, and those who had higher gender role identification femininity scores, $\beta=.17, p=.10$.

Research Question 6: Is there a difference between males and females in the direction of social comparison processes, gender role identification, self-efficacy, outcome expectancy, depression, and state-trait anxiety among young adults in pursuing their hoped-for possible selves?

Table 8 shows ANOVA results indicating that there was not a significant difference in the direction (upward or downward) of social comparison processes by gender, $F(1,152)=0.20, p=.655$. There was also not a significant interaction effect between the direction (upward or downward) of social comparison processes and gender, Wilks' lambda $F(1,152)=2.20, p=.138$. Although the difference between the females' downward social comparison processes $(\mathrm{M}=5.57)$ and upward social comparison processes $(\mathrm{M}=3.00)$ means was larger than the difference for those of males (downward $\mathrm{M}=5.21$, and upward $\mathrm{M}=3.16$ ), it was not significantly different. However, there was a significant difference among both males and females in the reported degree of importance between upward and downward social comparison processes, Wilks' lambda $F(1,152)=$ $162.34, p<.001$. For both genders, upward social comparison processes were more important $(M=3.06)$ than downward social comparison processes $(M=5.39)$, with scores ranging from 1 indicating "very important" to 7 indicating "not important."

Table 9 shows ANOVA results indicating that there was a significant interaction effect between BSRI gender role identification scores and gender, Wilks' lambda $F$ 
$(2,161)=6.36, p=.002$. Post hoc tests using Fisher's LSD procedure at $p<.05$ showed that males' BSRI gender identification male scores $(M=4.54)$ were significantly greater than females' BSRI gender identification male scores $(M=4.32)$, whereas the females' BSRI gender identification female scores $(M=4.68)$ were significantly greater than males' females' BSRI gender identification female scores ( $M=4.49)$. However, there was not a significant difference between males and females in their BSRI gender identification neutral scores. In addition, for males, BSRI gender identification neutral scores $(M=4.32)$ were significantly less than BSRI gender identification male scores ( $M$ $=4.54)$ and BSRI gender identification female scores $(\mathrm{M}=4.49)$. However, female BSRI gender identification neutral scores $(\mathrm{M}=4.33)$ and male BSRI gender identification scores $(M=4.32)$ were significantly less than the female BSRI gender identification scores $(M=4.68)$. 


\section{DISCUSSION}

A preliminary goal of this study was to evaluate whether young adults tend to use social comparisons in developing their hoped-for possible selves and whether the gender of one's social comparison target has an impact upon the domains of one's identified hoped-for possible selves. Among the respondents who identified a hoped-for possible self within the Occupation domain, 52.6\% used a male social comparison target, compared to $47.4 \%$ who used a female social comparison target. Among the respondents who identified a hoped-for possible self within the Family domain, 83.3\% used a female social comparison target. Only $33 \%$ of those who chose the Abilities/Education domain and $38 \%$ of those who chose the Success domain used a female social comparison target. The small difference between using a male or female social comparison target in creating a hoped-for possible self within the Occupation domain shows that there has been a shift from the traditional female gender expectation of primarily having a family to an expectation toward also having an occupation.

A secondary goal of this study was to explore possible influences upon the selfregulatory processes of young adults related to their hoped-for possible selves. Therefore, in addition to exploring the impact of the gender of one's social comparison target on the type of future self envisioned by young adults, this study also evaluated the impact of two variables, (1) direction of social comparison processes (upward versus downward) and (2) gender role identification, upon young adults' self-regulatory processes toward achieving their hoped-for possible selves. When correlating the subjects' reported level of masculinity or femininity with self-regulatory processes, there were only 3 significant correlations: a greater sense of masculinity and greater self-efficacy, a greater sense of 
femininity and greater self-efficacy, and a greater sense of femininity and greater outcome expectancy. Femininity correlated with both self-efficacy and outcome expectancy, while masculinity did not correlate with outcome expectancy, providing implications for further research into other variables which influence the relationship between the masculine gender role identification and perceived expectations about achieving one's desired future self.

A third goal of this study was to evaluate whether there was a relation between young adults' self-regulatory processes and positive mental health outcomes (less trait anxiety, state anxiety, and depression). Among all young adult subjects in this study, a greater level of self-efficacy toward achieving hoped-for possible selves was significantly negatively correlated with symptoms of trait anxiety, state anxiety, and depression, while a greater level of outcome expectancy toward achieving hoped-for possible selves was significantly negatively correlated only with symptoms of trait anxiety.

My study applied Bandura's (1982) concept of self-regulatory processes (selfefficacy and outcome expectancy) to evaluate young adults' perceived ability to achieve hoped-for possible selves. This study also applied Festinger's social comparison theory and Bem's gender role theory to evaluate whether young adults' use of social comparisons affects their sense of self-efficacy and outcome expectancy. Bandura's (1989) research has linked self-efficacy to self-regulatory processes, which are daily behaviors triggered by both external standards of evaluation and internal self-observation processes, which serve as an ongoing monitoring and evaluative force within one's sense of the self. Bandura (1982) has supported the role of social comparisons in the development and maintenance of self-efficacy through his research findings that mastery 
experiences in comparison to others, modeling of others who have equal ability to either succeed or fail at a particular task, and attention given to a trusted person's encouraging words all increase one's sense of self-efficacy.

My study contributes to the current research on social comparisons, gender role identification, self-regulatory processes, and mental health outcomes during the pivotal transitional period from adolescence to young adulthood. Furthermore, this study was among the first to evaluate whether the gender of social comparison target influences young adults' domains of hoped-for possible selves, whether the direction of social comparison processes (upward or downward) influences young adults' self-regulatory processes related to achieving their hoped-for possible selves, whether gender role identification influences young adults' self-regulatory processes toward achieving their hoped-for possible selves, and whether these self-regulatory processes are indicators of positive mental health outcomes (less state anxiety, less trait anxiety, and less depression) among young adults.

\section{Limitations and Directions for Future Research}

Although the results of this study provide important implications for future research on social comparisons, gender role identification, self-regulatory processes, and positive mental health outcomes among young adults, several limitations can be noted. First, the small sample size of 164, consisting of only college students within the young adult age group, created a lack of generalizability to other types of young adults, such as those in the workforce or those lacking involvement in an educational or work environment. Secondly, the majority of this study's subjects $(67.7 \%)$ represented the Hispanic race/culture, thus limiting the generalizability of this study's findings to other 
ethnic groups. Thirdly, future research could use a larger variety of assessments measuring the specific self-regulatory activities used by young adults in working toward the achievement of their hoped-for possible selves and assessing other variables, such as previous academic performance and quality of relationship with one's parents.

Regarding this study's results, the lack of significant correlation between masculine gender role identification and outcome expectancy provides implications for further research into other variables which may influence the relationship between masculine gender role identification and young adults' perceived expectations about their competency in attaining desired future selves. Another limitation of this study was that there was no significant correlation between the direction of social comparison processes and young adults' sense of either self-efficacy or outcome expectancy toward achieving hoped-for possible selves, although, as described in this study's literature review, previous studies (Lockwood, 2002) have shown a relation between favorable upward social comparison processes and enhancement to one's ego by shifting oneself upward toward and perhaps beyond one's social comparison target. Finally, the lack of significant correlation between masculine gender role identification and outcome expectancy, compared to a significant correlation between feminine gender role identification and outcome expectancy, provides implications for further research into other variables which may influence the relationship between masculine gender role identification and perceived expectations about competency in attaining desired future selves.

This study addresses the need for further research on social comparisons (Buunk \& Gibbons, 1997), because social comparisons have been hypothesized to assist individuals in providing information on how they should change their behavior to obtain 
favorable outcomes (Gilbert, 1990; Gilbert, Price, \& Allan, 1995, as cited in Buunk \& Gibbons, 1997) and have been correlated with depressed mood states and deprecatory thoughts about the self (Weary \& Edwards, 1994, as cited in Buunk \& Gibbons, 1997). Furthermore, this study contributes to understanding the cognitive evaluations regarding the strengths and weaknesses between oneself and others and exploring the impact of these evaluations on mental health outcomes, general well-being, and sense of self. The assessments used in this study can be applied to a greater diversity of young adults, such as those in other geographic locations of the United States, so that more information is available in creating both educational self-awareness programs and mental health intervention programs for young adults. This study provides important implications for further exploration into the crucial developmental period of young adulthood and how young adults' mental, emotional, and behavioral processes are influenced by social comparisons and sense of gender role identity and, in turn, are influential in determining one's perceptions about the ability to attain desirable life goals. 


\section{REFERENCES}

Albert, S. (1977). Temporal comparison theory. Psychological Review, 84, 485-503.

Alicke, M.D. (1985). Global self-evaluation as determined by the desirability and controllability of trait adjectives. Journal of Personality and Social Psychology,49,16211630.

Alicke, M.D. (2000). Evaluating social comparison targets. Handbook of Social Comparisons:Theory and Research.

Alicke, M.D., LoSchiavo, F.M., Zerbst, J.L., \& Zhang, S. (1997). The person who outperforms me is a genius: Esteem maintenance in upward social comparison. Journal of Personality and Social Psychology, 73, 781-789.

Anderman, E.M., Anderman, L.H., \& Griesinger, T. (1999). The relation of present and possible academic selves during early adolescence to grade point average and achievement goals. The Elementary School Journal, 100, 3-17.

Aspinwall, L.G. \& Taylor, S.E. (1993). The effects of social comparison direction, threat, and self-esteem on affect, self-evaluation, and expected success. Journal of Personality and Social Psychology, 64, 708-722.

Anthis, K.S., Dunkel, C.S., and Anderson, B. (2004). Gender and identity status differences in late adolescents ' possible selves. Journal of Adolescence, 27, 147-152.

Baltes, P. (1987). Theoretical propositions of life-span developmental psychology: On the dynamics between growth and decline. Developmental Psychology, 23(5), 611-626.

Bandura, A. (1982). Self-efficacy in human agency. American Psychologist, 37, 122-147.

Bandura, A. (1989). Regulation of cognitive processes through perceived self-efficacy. Developmental Psychology, 25, 729-778.

Barnes, Jonathan (ed.) (1984). The complete works of Aristotle: The revised oxford translation (volume one). Princeton/Bollingen: Princeton University Press, Series XXI, 2.

Beach, S.R.H. \& Tesser, A. (2000). Self-evaluation maintenance and evolution: Some speculative notes. In J. Suls \& L. Wheeler (Eds.), Handbook of social comparison: Theory and research, 159-172. New York: Kluwer Academic/Plenum Publishers.

Bem, S.L. (1974). The measurement of psychological androgyny. Journal of Consulting and Clinical Psychology, 42, 155-162. 
Bem, S.L. (1981). Gender schema theory: A cognitive account of sex typing source. Psychological Review, 88, 354.

Bem, S.L. (1981) The BSRI and gender schema theory: A reply to Spence and Helmreich. Psychological Review, 88, 369-71.

Bem, S.L. (1993). The lenses of gender: Transforming the debate on sexual inequality. New Haven, CT: Yale University Press.

Bittner, C.J. (1931). G.H. Mead's social concept of the self. Sociology and Social Research, 16, 6-22.

Blumer, H. (1969). Symbolic interactionism: Perspectives and methods. Berkeley: UC Press.

Brandtstadter, J. (1989). Personal self-regulation of development: Cross-sectional analyses of development-related control beliefs and emotions. Developmental Psychology, 25, 96-108.

Brandtstadter, J. (1999). Sources of resilience in the aging self: Toward integrating perspectives. In T.M. Hess \& F. Blanchard-Fields (Eds.), Social cognition and aging, 125-141. San Diego, CA: Academic Press.

Brandtstadter, J. \& Lerner, R.M. (1999). Action and self-development: Theory and research through the life span. Thousand Oaks, CA: Sage Publications, Inc.

Breytspraak, L.M. (1984). The development of the self in later life. Little, Brown, and Company.

Bronfenbrenner, U. (1979). The ecology of human development: Experiments by nature and design. Cambridge, MA: Harvard University Press.

Buunk, B.P., Collins, R.L., Taylor, S.E., Dakof, G., \& Van Yperen, N. (1990). The affective consequences of social comparison: Either direction has its ups and downs. Journal of Personality and Social Psychology, 59, 1238-1249.

Carstensen, L.L. \& Lockenhoff, C.E. (2003). Aging, emotion, and evolution: The bigger picture. Annals of the New York Academy of Science, 152-179

Chalk, L.M., Meara, N.M., \& Day, J.D. (1994). Possible selves and occupational choices. Journal of Career Assessment, 2, 364-383.

Collins, R.L. (1996). For better or worse: The impact of upward social comparison on self-evaluations. Psychological Bulletin, 119, 51-69. 
Collins, R.L. (2000). Among the better ones: Upward assimilation in social comparison. In J. Suls \& L. Wheeler (Eds.), Handbook of social comparison: Theory and research, (pp. 159-172). New York: Kluwer Academic/Plenum Publishers.

Cooley, C.H. (1902). Human nature and the social order. New York: Scribner's Press.

Cross, S. \& Markus, H. (1991). Possible selves across the lifespan. Human Development, $34,230-255$.

Dewey, J. (1896). The reflex arc concept in psychology. Psychological Review, 3, 357370.

Dreyfus, H.L. (1991). Being in the world: A commentary on Heidegger's being and time (division I). MIT Press: Cambridge, MA, London.

Dunkel, C. (2000) Possible selves as a mechanism for identity exploration. Journal of Adolescence, 23, 519-529.

Dunkel, C. \& Kerpelman, J. (2006) Temporal comparisons, identity, and motivation: The relation between past, present, and possible future selves. Possible Selves: Theory, Research, and Applications. Hauppage, NY: Nova Science Publishers.

Dunkel, C., Kelts, D., Coon, B. (2006) Possible selves as mechanisms of change in therapy. In Dunkel, C. (Ed); Kerpelman, J. (Ed). Possible Selves: Theory, Research and Applications. (pp. 187-204). Hauppauge, NY: Nova Science Publishers.

Eccles, J. S. (1996). The power and difficulty of university-community collaboration. Journal of Research on Adolescence, 6, 81-86.

Elder, G. H. (1998a). The life course and human development. In R. M. Lerner (Ed.), Handbook of child psychology, Vol 1: Theoretical models of human development. New York, NY: Wiley.

Erikson, E. H. (1959). Identity and the life cycle. New York: Norton.

Erikson, E. H. (1968). Identity: Youth and crisis. New York: Norton.

Erikson, E.H. (1970). Reflections on the dissent of contemporary youth. International Journal of Psychoanalysis, 51, 11-22.

Festinger, L. (1954). A theory of social comparison processes. Human Relations, 7, 117140.

Festinger, L. (1950). Informal social communication. Psychological Review, 57, 271-282. 
Ford, D.H. \& Lerner, R.M. (1992). Developmental systems theory: An integrative approach. Newbury Park, CA: Sage Publications, Inc.

Frazier, L.D., Cotrell, V., \& Hooker, K. (2003). Possible selves and illness: A comparison of individuals with Parkinson's disease, early-stage Alzheimer's disease, and healthy older adults. International Journal of Behavioral Development, 27, 1-11.

Frazier, L.D. \& Hooker, K. (2006). Possible selves in adult development: Linking theory and research. In C. Dunkel \& J. Kerpelman (Eds.) Possible selves: Theory, research, and application. Huntington, NY: Nova Science Publishers.

Frazier, L.D., Hooker, K., Johnson, P.M., \& Kaus, C.R. (2000). Continuity and change in possible selves in later life: A five-year longitudinal study. Basic and Applied Social Psychology, 22, 237-244.

Frazier, L.D., Johnson, P.M., Gonzalez, G.K., \& Kafka, C.L. (2002). Psychosocial influences on possible selves: A comparison of three cohorts of older adults. International Journal of Behavioral Development, 26, 308-326.

Frazier, L.D., Montgomery, M., Hinton, H., Perez, A., Barreto, M., \& Jauregui, J. (2003). Who Shapes the Future? The Role of Others in Young Adults' Possible Selves. Manuscript submitted on 04/11/03 at Florida International University.

Freud, S. (1900). The interpretation of dreams. In standard edition (Vols. 4 \& 5).

Freud, S. (1917). Introductory lectures on psychoanalysis. In standard edition (Vols. 15 \& 16).

Freud, S. (1923). The ego and the id. In standard edition (Vol. 19).

Fromm, E. (1941) Escape from freedom. New York: Holt, Rinehart, and Winston.

Goffman, E. (1959). Presentation of self in everyday life. Doubleday Anchor Books: Carden City, NY

Hogg, M.A. \& Abrams, D. (1988). Social identifications:A social psychology of intergroup relations and group processes. Routledge: London.

Hogg, M.A. \& Abrams, D. (1999). Social identity and social cognition. Blackwell: Oxford, England.

Hooker, K. (1999). Possible selves in adulthood: Incorporating teleonomic relevance into studies of the self. In T. Hess \& F. Blanchard-Fields (Eds.) Social cognition and aging (pp. 97-122). San Diego, CA: Academic Press. 
Hooker, K. \& Kaus, C.R. (1994). Health-related possible selves in young and middle adulthood. Psychology and Aging, 9, 126-133.

Hope, R. (1952). Aristotle: Metaphysics. University of Michigan Press: Ann Arbor.

James, W. Principles of psychology. New York: Henry Holt.

Jung, C.G. (1928). On psychic energy. In collected works (Vol. 8).

Jung, C.G. (1954). Archetypes and the collective unconscious. In collected works (Vol. 9, Part 1).

Jung, C.G. (1964). Man and his symbols. Garden City, New York: Doubleday.

Kemmelmeier, M. \& Oyserman, D. (2001). Gendered influence of downward social comparisons on current and possible selves. Journal of Social Issues, 57, 129-148.

Kemmelmeier, M. \& Oyserman, D. (2001). The ups and downs of thinking about a successful other: Self-construals and the consequences of social comparisons. European Journal of Social Psychology, 31, 311-320.

Lerner, R.M. \& Busch-Rossnagel, N.A. (1981). Individuals as producers of their development: conceptual and empirical bases. In R.M. Lerner \& N.A. Busch- Rossnagel (Eds.), Individuals as producers of their development: A life-span perspective (pp. 1-36). New York: Academic Press.

Lockwood, P. (2002). Could it happen to you? Predicting the impact of downward comparisons on the self. Journal of Personality and Social Psychology, 82, 343-358.

Markus, H. (1983). Self-knowledge: An expanded view. Journal of Personality, 51 (3), 542-565.

Markus, H., \& Nurius, P. (1986). Possible selves. American Psychologist, 41(9), 954969.

Markus, H., Kemmelmeier, \& Oyserman, D. (2001). Gendered influence of downward social comparisons on current and possible selves. Journal of Social Issues 57(1), 129148.

Maslow, A.H. (1943). A theory of human motivation. Psychological Review, 50, 370396.

Maslow, A.H. (1968). Toward a psychology of being (2 ${ }^{\text {nd }}$ ed.). New York: Van Nostrand. 
Masten, A.S. (2001). Ordinary magic: Resilience processes in development. American Psychologist, 56(3), 227-238.

Mead, G.H. (1932). Mind, self, and society. Chicago, IL: University of Chicago Press.

Ormrod, J. (2006). Educational Psychology: Developing Learners. Upper Saddle River, N.J.: Pearson/Merrill Prentice Hall.

Oyserman, D. (1987). Possible selves and behavior: The case of juvenile delinquency. Unpublished doctoral dissertation, University of Michigan, Ann Arbor.

Oyserman, D., \& Markus, H. R. (1990). Possible selves and delinquency. Journal of personality and social psychology, 59(1), 112-125.

Oyserman, D. (1997). Collectivism, personal autonomy, wealth and cognitive competence. Contemporary Psychology, 42, 790-792.

Oyserman, D. \& Fryberg, S. (2006). The possible selves of diverse adolescents: Content and function across gender, race, and national origin. In Dunkel, C., Kerpelman, J. (Eds.) Possible selves: Theory, research, and applications (pp. 17-39). Hauppauge, NY: Nova Science Publishers.

Oyserman, D., Kemmelmeier, M., Fryberg, S., Brosh, H., \& Hart-Johnson, T. (2003). Racial-ethnic self-schemas. Social Psychology Quarterly Special: Race, Racism, and Discrimination, 66(4), 333-347.

Oyserman, D. \& Markus, H. (1990b). Possible selves in balance: Implications for delinquency. Journal of Social Issues, 46(2), 141-157

Parsons, R., Hinson, S., Sardo-Brown, D. (2001). Educational Psychology: PractitionerResearcher Model of Teaching. Australia, Canada, Singapore, Spain, United Kingdom, United States: Wadsworth.

Rogers, C.R. (1947). Some observations on the organization of personality. American Psychologist, 2, 358-368.

Santrock, J., Woloshyn, V., Gallagher, T., Di Petta, T., Marini, Z. (2007). Educational Psychology. Toronto: McGraw-Hill Ryerson.

Suls, J. \& Willis, T.A. (Eds.). (1991). Social comparison: Contemporary theory and research. Hillsdale, NJ: Lawrence Erlbaum.

Suls, J. \& Wheeler, L. (Eds.). (2000). Handbook of social comparison: Theory and research. New York: Kluwer Academic/Plenum Publishers. 
Symonds, J.E. (2004). Year 11 pupils' education and employment possible selves: The methodological challenges of measuring representational constructs. University of Cambridge, Faculty of Education.

Tajfel, H. (1959). Quantitative judgment in social perception. British Journal of Psychology, 50, 16-29.

Taylor, S.E. \& Lobel, M. (1989). Social comparison activity under threat: Downward evaluation and upward contact. Psychological Review, 96, 569-575.

Wheeler, L. (2000). Individual differences in social comparison. In J. Suls \& L. Wheeler (Eds.), Handbook of social comparison: Theory and research, (pp. 141-158). New York: Kluwer Academic/Plenum Publishers.

Wheeler, L. \& Miyake, K. (1992). Social comparison theory in everyday life. Journal of Personality and Social Psychology, 62, 760-773.

Wills, T.A. (1981). Downward comparison principles in social psychology. Psychological Bulletin, 90, 245-271.

Woolfolk, A. et al. (2006). Educational Psychology: Third Canadian Edition. Toronto: Pearson Education Inc. 174-175.

Zell, E. \& Alicke, M.D. (2009). Journal of Experimental Social Psychology, 45(1), 223227. 


\section{DATA ANALYSIS RESULTS}

Table 1. Demographic Characteristics of Respondents

\begin{tabular}{lrr}
\hline & $\%$ & $\mathrm{~N}$ \\
\hline Total Respondents & 100.0 & 164 \\
& & \\
Gender & & \\
Female & 61.6 & 101 \\
Male & 38.4 & 63 \\
& & \\
Race & & \\
Hispanic & 67.7 & 111 \\
White Caucasian & 12.2 & 20 \\
African-American & 7.3 & 12 \\
Asian & 3.7 & 6 \\
West Indian & 1.2 & 2 \\
Other & 7.9 & 13 \\
& & \\
Ethnicity & & \\
Hispanic Yes & 67.7 & 111 \\
Hispanic No & 32.3 & 53 \\
Age (years) [M = (18), SD = ] & & \\
17-20 & 83 & 136 \\
21-24 & 9.7 & 16 \\
25-30 & 7.3 & 12 \\
& & \\
& & \\
Highest Degree & & \\
Partial High School & $6 \%$ & 1 \\
High School Graduate & $22 \%$ & 36 \\
Partial College & & \\
College Graduate & & \\
Graduate or Professional Degree & $1.2 \%$ & 2 \\
\hline
\end{tabular}


Table 2. Summary of Cross-tabulation Results for Gender of Social Comparison Target by 5 Hoped-For Possible Self Domains $(\mathrm{N}=110)$.

Hoped-For Possible Self Sex of the person you compare yourself to

Male $\quad$ Female

\begin{tabular}{lllll} 
& $\mathrm{N}$ & $\%$ & $\mathrm{~N}$ & $\%$ \\
\hline Personal & 6 & 54.5 & 5 & 45.5
\end{tabular}

$\begin{array}{lcccc}\text { Abilities and Education } & 14 & 66.7 & 7 & 33.3 \\ \text { Family } & 4 & 16.7 & 20 & 83.3 \\ \text { Occupation } & 20 & 52.6 & 18 & 47.4 \\ \text { Success } & 10 & 62.5 & 6 & 37.5\end{array}$

Table 3. Summary of Correlation Results for Direction of Social Comparison Processes and Self-Regulatory Processes $(\mathrm{N}=155)$.

$\begin{array}{ll}\text { Downward Social } & \begin{array}{l}\text { Upward Social } \\ \text { Comparison }\end{array} \\ \text { Comparison }\end{array}$

$\begin{array}{lll}\text { PSQ Self-Efficacy } & -.12(n s) & -.12(n s) \\ \text { PSQ Outcome } & -.13(n s) & -.14(n s) \\ \text { Expectancy } & & \end{array}$

Note. $n s=$ not significant

For both downward and upward social comparison processes: $1=$ very important to $7=$ not important. 
Table 4. Summary of Correlation Results for BSRI Gender Role Identification and SelfRegulatory Processes $(\mathrm{N}=164)$.

\section{BSRI Masculine BSRI Neutral BSI Feminine}

$\begin{array}{llll}\text { PSQ Self-Efficacy } & .16^{*} & .13 & .15^{*} \\ \text { PSQ Outcome } & .09 & .12 & .21^{* *}\end{array}$

Expectancy

Note. ${ }^{*} p<.05, * * p<.01$

For self-efficacy and outcome expectancy scores, $1=$ not important to $7=$ very important.

Table 5. Summary of Correlation Results for Self-Regulatory Processes and Mental Health Outcomes $(\mathrm{N}=164)$.

\begin{tabular}{lccc}
\hline & State Anxiety & Trait Anxiety & Depression \\
PSQ Self-Efficacy & $-.33^{* *}$ & $-.36^{* *}$ & $-.26^{* *}$ \\
PSQ Outcome & $-.14(n s)$ & $-.21^{* *}$ & $-.12(n s)$ \\
Expectancy & & & \\
\hline
\end{tabular}

Note. ${ }^{*} p<.05, * * p<.01, n s=$ not significant.

Depression: $0=$ none, $60=$ very much. State anxiety: $20=$ not much, $80=$ very much. Trait anxiety: $10=$ not much, $80=$ very much.

Table 6. Multiple Regression Model Summary: Self-Regulatory Processes

\begin{tabular}{lccccc}
\hline & R Square & R Square Change & df & F Change & F \\
Self-Efficacy & .22 & $.19^{* *}$ & 8 & $4.36^{* *}$ & $3.32^{* *}$ \\
Outcome Expectancy & .15 & $.12^{*}$ & 12 & $2.47^{*}$ & $2.12^{*}$
\end{tabular}

Note. $* p<.05, * * p<.01$.

Self-efficacy: $1=$ not much, $7=$ very much. Outcome expectancy: $1=$ not much, $7=$ very much. 
Table 7. Multiple Regression Analysis of Self-Regulatory Processes on Independent Variables, Controlling for Demographic Variables: Standardized Coefficients

\begin{tabular}{lcc}
\hline & Age & Trait Anxiety \\
Self-Efficacy & $.22^{*}$ & $-.35^{*}$ \\
Outcome Expectancy & $.26^{*}$ & $-.31^{*}$ \\
& & \\
\hline
\end{tabular}

Note. $* p<.05, * * p<.01$.

Self-efficacy: $1=$ not much, $7=$ very much. Outcome expectancy: $1=$ not much, $7=$ very much.

Table 8. Multivariate Tests of Direction of Social Comparison Processes by Gender

\section{Wilks’ Lambda F}

Direction of Social Comparison $\quad 162.34 * *$

Processes

Direction of Social Comparison 2.22 (ns)

Processes by Gender

Note. ${ }^{*} p<.05, * * p<.01, n s=$ not significant.

For both downward and upward social comparison processes: $1=$ very important to $7=$ not important. 
Table 9. Multivariate Tests of BSRI Gender Role Identification by Gender

\section{Wilks' Lambda F}

BSRI Gender Role Identification

$32.48^{* *}$

BSRI Gender Role Identification by

$6.36^{* *}$

Gender

Note. $* p<.05, * * p<.01$

BSRI gender identification scores for masculinity, femininity, and neutral: $1=$ never true of me, 7 = always true of me.

Table 10. Multivariate Tests of Self-Regulatory Processes by Gender

\section{Wilks' Lambda F}

Self-Regulatory Processes

$7472.08^{*}$

Self-Regulatory Processes by

$.99(n s)$

Gender

Note. ${ }^{*} p<.05, * * p<.01, n s=$ not significant 
VITA

REBECCA ANN WANG

Miami, FL 33133

\section{EDUCATION}

10/12 PhD, Developmental Psychology

Florida International University

Miami, FL 33199

11/10 M.S., Developmental Psychology

Florida International University

Miami, FL 33199

08/93 M.S. Ed., Counseling Psychology

University of Miami

Coral Gables, FL 33143

07/89 B.A., Social Psychology

Tufts University

Medford, MA 02155

\section{PROFESSIONAL EXPERIENCE}

10/09-Present Full-Time Psychology Professor

International University of Art and Design - Miami, FL

Courses Taught: Introduction to Psychology, Social Psychology, Theories

of Personality

01/08-09/09 Adjunct Psychology Professor

Miami International University of Art and Design - Miami, FL

Courses Taught: Introduction to Psychology, Social Psychology

08/04-12/07 Graduate Research Assistant

Florida International University - Miami, FL

Contributed to a community-based youth intervention project through

facilitation of group therapy sessions at an alternative high school and

through statistical analyses of research data generated from this project

05/05-05/07 Adjunct Psychology Professor

Florida International University - Miami, FL 
Courses Taught: Research Methods, Developmental Psychology, Psychotherapy

10/01-08/04 Treatment Coordinator

Care Connection, Inc. - Odenton, MD

Developed and reviewed treatment plans for adult bipolar and schizophrenic patients at a community-based agency

12/96-11/98 Primary Mental Health Therapist Children's Psychiatric Center, Inc. - Miami, FL

Provided individual mental health therapy for children and adolescents at a community-based agency

12/95-12/96 Social Worker

Miami Bridge, Inc. - Miami, FL

Provided crisis intervention and individual mental health therapy for children and adolescents at an emergency shelter

03/94-11/95 Mental Health Therapist

Spectrum Programs, Inc. - Miami, FL

Provided individual and group mental health therapy at an adult outpatient substance abuse treatment center

\section{CONFERENCE PRESENTATIONS}

March, 2007 Positive Youth Development and Identity Formation in Adolescents Presented at the Society for Identity Formation, Washington, D.C. 